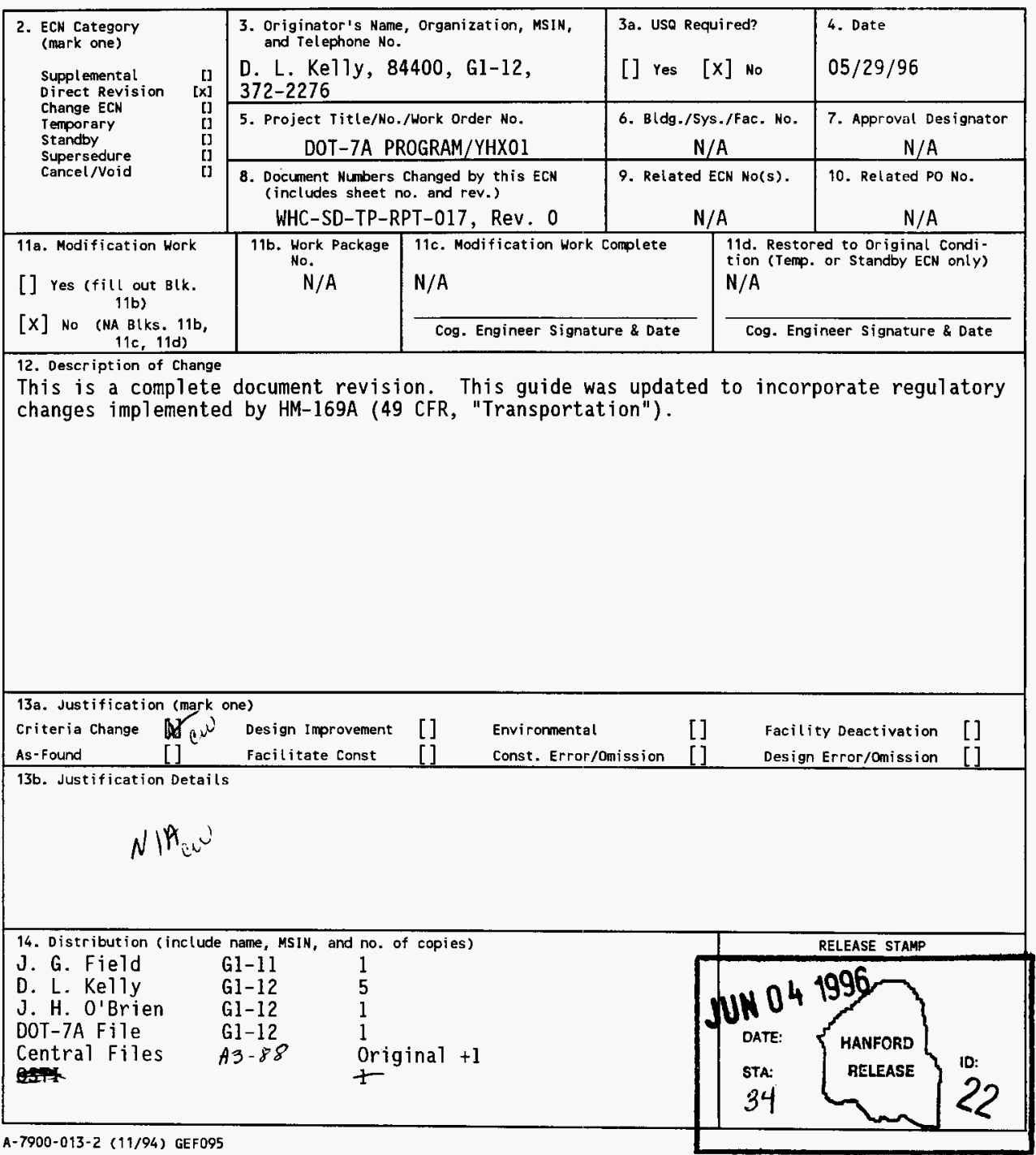




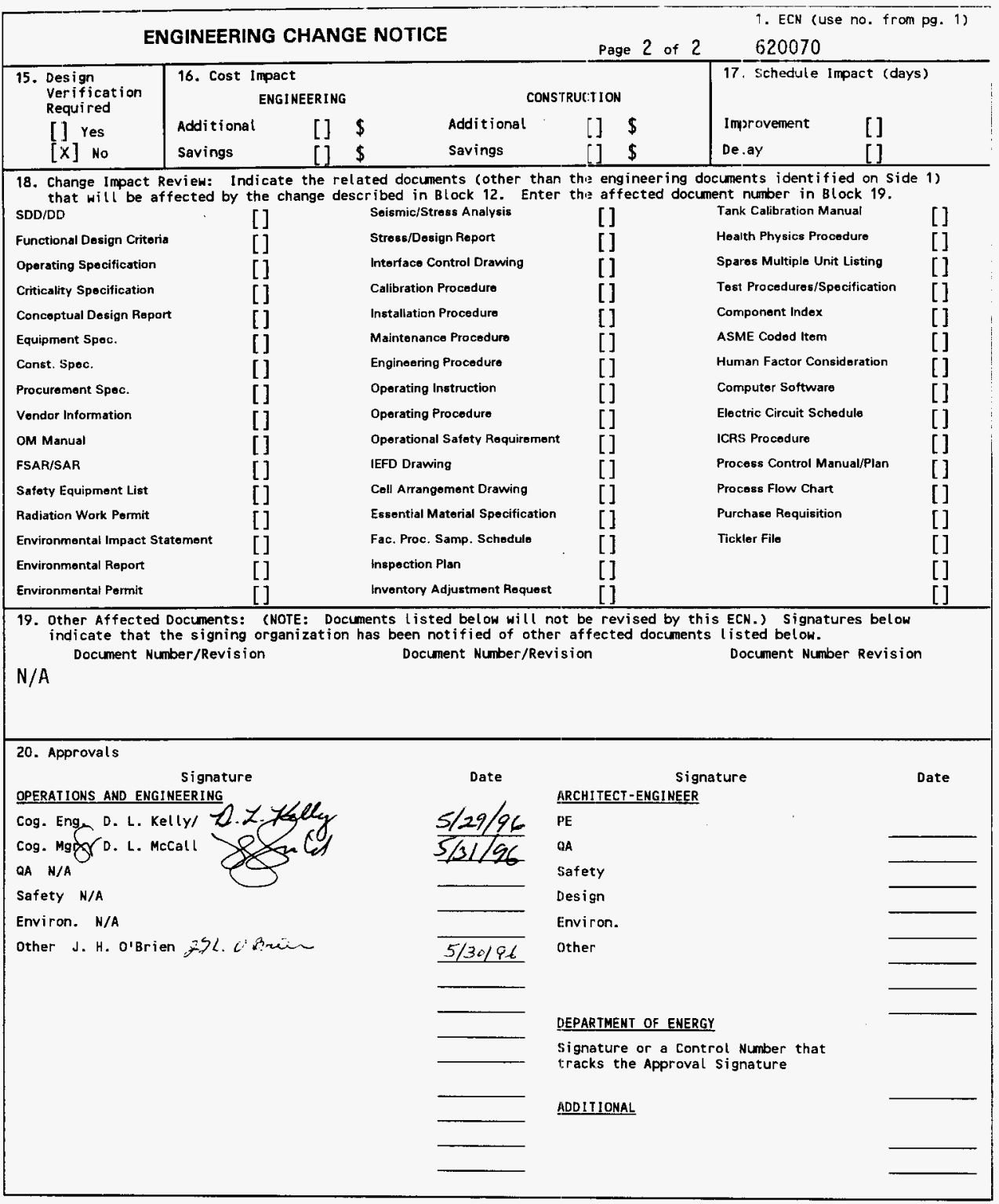




\title{
REGULATORY COMPLIANCE GUIDE FOR DOT-7A TYPE A PACKAGING DESIGN
}

\author{
D. L. Kelly
}

Westinghouse Hanford Company, Richland, WA 99352

U.S. Department of Energy Contract DE-AC06-87RL10930

\author{
EDT/ECN: $\quad 620070$ \\ Org Code: 84400 \\ UC: 722 \\ B\&R Code: HAOI20000 \\ Charge Code: YHXOI \\ Total Pages: theres
}

Key Words: Regulatory compliance, design guide, D0T-7A, Type A, package, packaging, radioactive material

Abstract: The purpose of this guide is to provide instruction for assuring that the regulatory design requirements for a DOT-7A Type $A$ packaging are met. This guide also supports the testing and evaluation activities that are performed on new packaging designs by a DOE-approved test facility through the DOE's DOT-7A Test Program. This guide was updated to incorporate regulatory changes implemented by HM-169A (49 CFR, "Transportation").

TRADEMARK DISCLAIMER. Reference herein to any specific comercial product, process, or service by trade name, trademark, manufacturer, or otherwise, does not necessarily constitute or imply its endorsement, recommendation, or favoring by the United States Government or any agency thereof or its contractors or subcontractors.

Printed in the United States of America. To obtain copies of this document, contact: WHC/BCS Document Control Services, P.O. Box 1970, Mailstop H6-08, Richland WA 99352, Phone (509) 372-2420; Fax (509) 376-4989.
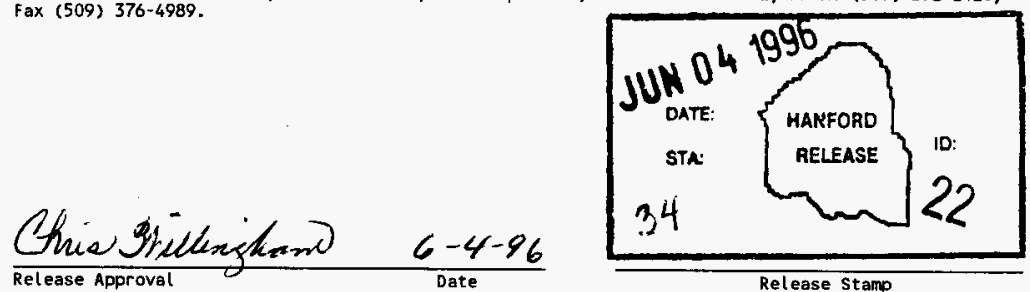
(2) Iitle

REGULATORY COMPLIANCE GUIDE FOR DOT-7A TYPE A PACKAGING DESIGN

CHANGE COHTROL RECORD

\begin{tabular}{|c|c|c|c|}
\hline \multirow{2}{*}{ Revision } & \multirow{2}{*}{ (4) Description of Change - Replace, Add, and Delete Pages } & \multicolumn{2}{|c|}{ Authorized for Release } \\
\hline & & (5) Cog. Engr. & (6) Cog. Mgr. \\
\hline 0 & (7) EDT \#608457 & & \\
\hline $\begin{array}{l}1 \\
R S\end{array}$ & $\begin{array}{l}\text { ECN \#620070 } \\
\text { Full document revision. Incorporates } \\
\text { HM-169A regulation changes applicable to } \\
49 \text { CFR, "Transportation" }\end{array}$ & $\begin{array}{l}\text { D.L. Kelly/ } \\
\text { 1.7. Helly } \\
5 / 29 / 96\end{array}$ & S. \\
\hline & & & \\
\hline & & & \\
\hline & & & \\
\hline & & & \\
\hline & & & \\
\hline & & & \\
\hline & & & \\
\hline & & & \\
\hline & & & \\
\hline & & & \\
\hline & & & \\
\hline & & & \\
\hline & & & \\
\hline & & & \\
\hline & & & \\
\hline & & & \\
\hline & & & \\
\hline & & & \\
\hline & & & \\
\hline & & & \\
\hline & & & \\
\hline & & & \\
\hline & & & \\
\hline & & & \\
\hline & & & \\
\hline & & & \\
\hline & & & \\
\hline
\end{tabular}


WHC-SD-TP-RPT-017

Revision 1

\section{CONTENTS}

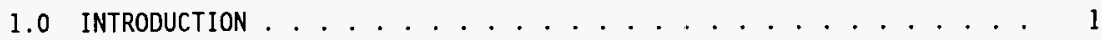

2.0 CHARACTERIZATION OF CONTENTS . . . . . . . . . . . . 2

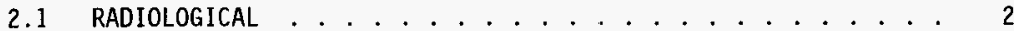

2.2 PHYSICAL FORM ................. 3

2.3 THERMAL ................... 4

2.4 CHEMICAL ................... 5

3.0 PACKAGING DESIGN . . . . . . . . . . . . . . . . . 6

3.1 DESIGN DOCUMENTATION ............... 7

3.1 .1 Drawing . . . . . . . . . . . . . . . . . 8

3.1.2 Specification ................ . . . 9

3.1.3 Analysis Report . . . . . . . . . . . . . . . . . . 9

3.3 CONTAINMENT . . . . . . . . . . . . . . . . . . 10

3.4 SHIELDING . . . . . . . . . . ....... 11

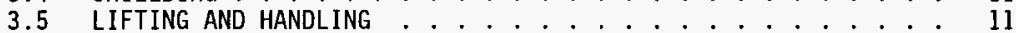

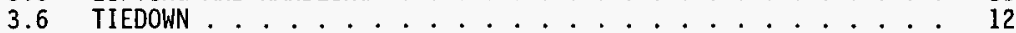

4.0 PACKAGING OPERATIONS . . . . . . . . . . . . . . . . . . 12

4.1 GENERAL . . . . . . . . . . . . . . . . . 12

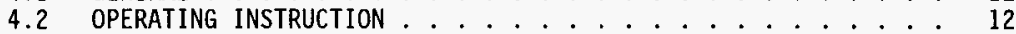

5.0 PACKAGING QUALIFICATION CHECKLIST . . . . . . . . . 14

6.0 PREPARATIONS FOR TESTING . . . . . . . . . . . . . . 14

6.1 PROOF TESTING . . . . . . . . . . . . . . . . . . 14

6.1 .1 Considerations - Water Spray Test . . . . . . . . 15

6.1 .2 Considerations - Reduced Pressure Test . . . . . . 15

7.0 REFERENCES . . . . . . . . . . . . . . . . . 16

8.0 GLOSSARY . . . . . . . . . . . . . . . . . . . 16

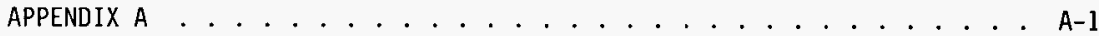

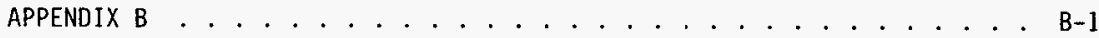


WHC-SD-TP-RPT-017

Revision 1

\section{REGULATORY COMPLIANCE GUIDE FOR DOT-7A TYPE A PACKAGING DESIGN}

\subsection{INTRODUCTION}

The purpose of this guide is to provide instruction for assuring that the regulatory designing requirements for a U.S. Department of Transportation Specification $7 A$ (DOT-7A) Type A packaging are met. Another purpose for this guide is to support the evaluation and testing activities that are performed on new packaging designs by a U.S. Department of Energy (DOE) test facility. The test facilities are located at various DOE sites, and are operated under the direction of DOE-Headquarters ( $\mathrm{HQ})$, Office of Transportation, Emergency Management, and Analytical Services (EM-76). This evaluation and testing program is called the DOT-7A Program.

This guide should be used when a need for a Type A packaging has been identified, and no currently qualified design or any design available from commercial suppliers will suffice. In this case, the organization responsible for the shipments (the shipper) must develop and qualify a packaging. By qualifying the packaging through the DOE DOT-7A Program, the acceptability and use of the packaging throughout the DOE community is enhanced. Qualifying a Type A packaging through the DOE DOT-7A Program is accomplished by contacting EM-76, and requesting a docket be opened. The person or organization sponsor requesting a test docket is referred to herein as the applicant.

The Type A packaging development process is initiated when the applicant has determined that a DOT-7A, Type A packaging is needed and that no currentiy qualified designs or commercially available designs will suffice. Characterization of the material to be shipped should have already been performed to the extent needed to conclude that no available packagings are adequate. Design of a packaging requires the material to be characterized to some minimal level to ensure that the new design will be adequate. Accordingly, the first step in this guide focuses on content characterization. Content characterization generates important parameters to be considered in the design process.

The design of a DOT-7A, Type A packaging, in accordance with this document, will generate the following items. When qualifying the packaging through the DOT-7A Program, these items are forwarded to a DOE-approved test facility to be reviewed for completeness before the evaluation and testing activities are conducted.

- Packaging drawing

- Packaging specification

(Optional, if needed to supplement drawing) 
WHC-SD-TP-RPT-017

Revision 1

- Analys is report

- Operating instruction

- Packaging Qualification Checklist (PQCL.).

The PQCL is a checklist created to assure that all of the DOT-7A regulatory design requirements are addressed during the development of a Type A package. The design process will produce the information needed for the completion of the $\mathrm{PQCL}$ (see Appendix B).

When a package is qualified through the COE DOT-7A Program, the DOT-7A Program team (located at a DOE-approved test facility) reviews these documents and resolves any comments with the applicant. The applicant will then prepare a sufficient number of prototype test units to satisfy the test requirements. The test units are then sent to the DOE-approved test facility where the final evaluations and performance testing are completed.

Packagings must be designed such that when subjected to the tests specified in Title 49 Code of Federal Regulations (49 CFR) 173.465, or evaluated against these tests by any of the methods authorized by 49 CFR 173.461(a), the packaging will prevent loss or dispersal of the radioactive contents, and any significant increase in the radiation levels recorded or calculated at the external surfaces for the condition before the test [49 CFR $173.412(j)]$.

The following sections detail the design process and the steps necessary to prepare for testing. Suggestions based on experience to date for materials and configurations are also included in the following sections.

\subsection{CHARACTERIZATION OF CONTENTS}

This section of the guide establishes what is considered the minimum level of characterization of the material to be shipped to support the design of a suitable packaging. It is not intended to define all aspects of content characterization that may be needed to fully document a shipment. The shipper is responsible for adequate content characterization to a level of detail to ensure compliance with the regulations.

\subsection{RADIOLOGICAL}

The following sections of 49 CFR pertain to the radiological characteristics of the material to be shipped:

173.417 Authorized fissile materials packages 
Addressing these requirements for the purpose of packaging design will require the development of a design basis list of the isotopes to be present in the contents and their expected quantity on a per-loaded-package basis (isotopic inventory). This list will be used for design purposes and will not reflect the actual contents shipped, but should establish bounding values on actual contents for design purposes. The applicant is requested to provide this list in the appropriate area in the PQCL. Further, if fissile radionuclides are present, the fissile classification shall be indicated.

The important parameters are (1) total activity allowed in the packaging, and (2) radiation level limits. Decay heat is covered in Section 2.3, Thermal.

\subsection{PHYSICAL FORM}

The physical form of the material has a direct and an indirect effect on the applicability of a number of requirements; for example, the form affects the density of the material, which will affect the gross weight, which affects the requirements invoked for package handling features. The Contents Characterization section of the PQCL contains check-off blocks for the basic physical form of the material to be shipped with blanks for additional data, based on the form.

Solid materials are defined in WHC-EP-0558, Test and Evaluation Document for DOT Specification 7A Type A Packaging (Cruse 1992), as follows:

Form Number 1: Solids - any particle size.

- A packaging qualified for these contents is expected to contain radioactive contents of any representative particulate size.

Form Number 2: Solids - large particle size only (i.e., sand, concrete, debris, soi1).

- Contents of a corresponding particulate size such as soil or construction debris. (Glass or plastic labware having fine particulate available for dispersion would not fit this category and would require a packaging qualified for fine particulate, Form Number 1.) 


\section{WHC-SD-TP-RPT-017}

Revision 1

Form Number 3: Solids - objects with no significant dispersible or removable contamination (for definition, see 49 CFR 173.443, Contamination Control).

- Metals with activation products

- Forms of metals/alloys/compounds of uranium, thorium

- Solid materials with the radioactive material firmly fixed in place, possibly by the application of a fixing media (i.e., paint)

- Solidified material.

NOTE: These are examples only and each form must be analyzed for compliance with the "no removable or dispersible contamination" criterion found in 49 CFR 173.443.

For heavy, bulky, materials (e.g., concrete chunks, motors, and pumps), equipment/materials with sharp corners or protrusions, or material/equipment geometries that could result in highly localized forces, the shipper must ensure that the contents are securely fastened/positioned within the package to prevent damage to the packaging.

Packaging intended to transport liquids and gases must be designed to withstand more severe test conditions than those designed for solids.

\subsection{THERMAL}

The following sections of 49 CFR pertain to the thermal limitations of packagings:

173.410(i) Air shipments, containment and shielding - temperature range

173.412(c) Containment and shielding - temperature range

173.442 Thermal limitations

173.448 (b) Heat output.

For whatever reason, the thermal heat generation of the contents must not degrade the packaging. Normally Type A quantities of radionuclides do not generate enough decay heat to be of concern. For any heat-generating contents, the decay heat should be calculated and documented in the package design analyzed to ensure no problems. The applicant shall indicate a maximum design wattage value for the contents in the appropriate block of the PQCL. 
WHC-SD-TP-RPT-017

Revision 1

\subsection{CHEMICAL}

The following sections of 49 CFR pertain to the chemical characteristics of the contents:

173.21

173.24 (b) (3)

$173.24(\mathrm{e})(2)$

173.24 (e) (3)

$173.24(f)$

$173.410(\mathrm{~g})$

$173.412(\mathrm{e})$
Forbidden materials and packages

Mixture, reaction

Reaction

Plastic compatibility/permeability

Closures, gaskets

Compatibility, behavior under irradiation

Gas generation, radiolysis.

The contents must not react with the packaging so as to degrade it. The contents must not possess or develop chemical conditions that could lead to pressurization beyond design specification or an explosion.

The basic chemical makeup of the nonradioactive constituents of the contents to be shipped must be understood to adequateiy design a packaging. The applicant shall identify any nonradioactive materials in the contents that meet the definition of hazardous materials in accordance with 49 CFR 172 . The applicant shall also identify all organic substances and the quantity expected to be present in a single package. The hazardous materials shall be listed by their proper shipping name and identification number in accordance with the Hazardous Materials Table (49 CFR 172.101). This information, or the document that the information may be found in, should be listed in the space provided in the PQCL.

Hydrogen gas generation has been a controlling parameter for a number of radioactive shipments. On September 10, 1984, the U.S. Nuclear Regulatory Commission (NRC) issued Information Notice Number 84.72, Clarification of Conditions for Waste Shipments Subject to Hydrogen Gas Generation (NRC 1984). The following generic requirements from that notice are included in certain Certificates of Compliance:

(1) For any package containing water and/or organic substances that could radiolytically generate combustible gases, it must be determined by tests and measurements of a representative package whether or not the following criteria are met over a period of time that is twice the expected shipment time:

(a) The hydrogen generated must be limited to a molar quantity that would be no more than $5 \%$ by volume (or equivalent limits for other inflammable gases) of the secondary container gas void, if present, at STP (i.e., no more than $0.063 \mathrm{~g}$-moles $/ \mathrm{ft}^{3}$ at 14.7 psia and $\left.70^{\circ} \mathrm{F}\right)$, or 
(b) The secondary container and cask cavity must be inerted with a diluent to ensure that oxygen must be limited to $5 \%$ by volume in those portions of the package that could have hydrogen greater than $5 \%$.

For any package delivered to a carrier for transport, the secondary container must be prepared for shipment in the same manner in which determination for gas generation is made. The shipment period begins when the package is prepared (sealed) and must be completed within twice the expected shipment time.

(2) For any package containing materials with radioactivity concentration not exceeding that for low specific activity (LSA) material, and shipped within 10 days of preparation, or within 10 days after venting of drums or other secondary containers, the determination in (1) above need not be made, and the time restriction in (1) above does not apply.

The notice also points out that the generation of combustible gases is dependent on the waste form, radioactive concentration and isotope, free volume, total mass and accumulated dose in the waste. This information should be considered when characterizing the packaging's contents.

\subsection{PACKAGING DESIGN}

The following sections of 49 CFR pertain to the design of a Type $A$ packaging:

173.24 (b)

$173.24(\mathrm{e})(3)$

173.403

173.410

173.412

$173.462(\mathrm{c})$

$173.462(d)$

178.3

Design and construction

$\mathrm{Plastic}$ packagings and receptacles

Definitions

General design requirements

Additional design requirements for Type A packages

Containment system...specified

External features...clearly identified

Marking of Packagings.

The designer should scan the data in WHC-EP-0558, Test and Evaluation Document for DOT Specification 7A Type A Packagings (Cruse 1992), and review designs qualified for similar contents for examples from which to work. Before beginning the design process, all regulatory requirements should be thoroughly reviewed and understood. For convenience, the applicable designrelated Type A packaging requirements have been excerpted and included as Appendix $A$ to this document. This material is for information on $7 y$ and cannot guarantee reflection of the latest revisions of the applicable regulations. 
WHC-SD-TP-RPT-C17

Revision 1

\subsection{DESIGN DOCUMENTATION}

The generation of adequate documentation for Type A packaging is important, as each offeror of a Type A packaging is required to have a copy of the documentation. The document should be maintained using a method that will allow the reproduction of clean usable copies. The regulatory requirements for the documentation are found in 49 CFR 173.415(a), "... Each offeror of a Specification 7A package must maintain on file for at least one year after the latest shipment, and shall provide to DOT on request, complete documentation of tests and an engineering evaluation or comparative data showing that the construction methods, packaging design, and materials of construction comply with that specification..." When deciding what documentation to maintain, the definitions in 49 CFR 173.403 should be consulted. The following definitions from that 1 ist are presented to show their importance.

Design means the description of a special form Class 7 (radioactive) material, a package, packaging, or LSA-III, that enables those items to be fully identified. The description nay include specifications, engineering drawings, reports showing compliance with regulatory requirements, and other relevant documentation.

Package means, for Class 7 (radioactive) materials, the packaging together with its radioactive contents as presented for transport...

(2) "Type A package" means a packaging that, together with its radioactive contents 1 imited to $A_{1}$ or $A_{2}$ as appropriate, meets the requirements of $\$ \$ 173.410$ and 173.412 and is designed to retain the integrity of containment and shielding required by this part under normal conditions of transport as demonstrated by the tests set forth in $\$ 173.465$ or $\S 173.466$, as appropriate...

Packaging means, for Class 7 (radioactive) materials, the assembly of components necessary to ensure compliance with the packaging requirements of this subpart. It may consist of one or more receptacles, absorbent materials, spacing structures, thermal insulation, radiation shielding, service equipment for filling, emptying, venting and pressure relief, and devices for cooling or absorbing mechanical shocks. The conveyance, tie-down system, and auxiliary equipment may sometimes be designated as part of the packaging.

The following areas of Section 3.0 present guidance on the types and contents of the required documentation, and subject areas to document. 
WHC-SD-TP-RPT-017

Revision 1

\subsubsection{Drawing}

A packaging general arrangement drawing which specifies the materials and components to the extent necessary to assure compliance and reliability of manufacturing of the packagings shall be prepared. Any materials forming the containment boundary or related to performance shall be specified by characteristics that will ensure that the manufactured packagings will be equivalent to the prototypes used in testing or to the design qualified by evaluation.

The regulatory requirements that pertain to the content and packaging suggest that the packaging drawing address the following:

1) The packaging should be identified by a simple alpha-numeric model number. If the drawing identifies a series of packagings of similar design, a different number should be used for each to avoid confusion.

2) If steel is used in the packaging, it should be specified and the specification reviewed to assure the steel is low-carbon, commercial quality steel. Stainless, open hearth, electric, basic oxygen, or other similar quality steels are acceptable.

3) If lumber is used in the packaging, it should be specified as being well seasoned, commercially dry, and free from decay, loose knots, knots that would interfere with nailing, and other defects that would materially lessen the strength.

4) If the construction process includes welding or brazing, the drawing should include guidance in order to ensure that welding or brazing are performed in a workmanlike manner using suitable and appropriate techniques, materials, and equipment.

5) Geometric tolerances in accordance with ANSI Y14.5M (ANSI 1982) should be used whenever applicable.

6) Packaging features that are critical to the design and performance shall be dimensioned with appropriate tolerances.

7) The containment system of the packaging should be clearly specified on the drawing [49 CFR $173.462(\mathrm{c})]$.

8) External features of the packaging system should be clearly identified on the drawing so that they may be easily referenced [ 49 CFR 173.462(d)]. 
WHC-SD-TP-RPT-017

Revision 1

9) A number of Type A packagings listed in the WHC-EP-0558, Test and Evaluation Document for DOT Specification 7A Type A Packaging (Cruse 1992), use components that were specified in 49 CFR 178 (i.e., DOT-17C Steel Drum). However, docket HM-181 (HM-181 1990) el iminated many of these specification packagings.

CAUTION: The eliminated packagings have been replaced with Performance-Oriented packagings (POP). The POP are now specified by particular UN performance designs. As the packagings are based on performance and not design, it is possible to have many packagings design meeting the same performance specification. For this reason, designers are cautioned not to refer to such specifications in the design documentation for new packagings. New packagings should be identified in enough detail to ensure that the same packaging design will be used each time that particular packaging configuration is manufactured.

\subsubsection{Specification}

A specification for the packaging design may or may not be needed depending on its complexity. If the drawing becomes overly burdened with information, it is recommended that a specification be prepared to supplement the drawing. The specification is a useful place to state material and processing requirements for the packaging components (i.e., steel, lumber, gaskets).

\subsubsection{Analysis Report}

The following sections of 49 CFR pertain to the analysis report which documents the adequacy of the packaging:

$173.410(\mathrm{~b}) \quad$ Lifting attachments

173.412(c) Liquid, brittle fracture (if applicable)

173.412(i) Tiedown, failure (if applicable)

173.441 Radiation level limitations (if shielding is required)

173.442 Thermal limitations.

The following sections of 49 CFR include a chemical compatibility evaluation that documents the regulatory requirements:

173.21

173.24 (b) (3)

$173.24(\mathrm{e})(2)$

$173.24(\mathrm{e})(3)$

$173.24(f)$
Forbidden materials and packages

No mixture of gasses and vapors

No significant chemical or galvanic reaction

Plastic packagings and receptacles

Closures shall be adequate 


\section{WHC-SD-TP-RPT-017}

Revision 1

$173.410(\mathrm{~g}) \quad$ Compatibility of packaging materials and contents

173.412(e) Gas generation/radiolytic decomposition/radiolysis.

The analysis report shall be of sufficient detail so that it can be verified by an independent overcheck.

\subsection{GENERAL ARRANGEMENT}

The packaging design will generally fall into one of three basic configurations: (1) single packaging, (2) composite packaging, or (3) combination packaging (for definitions see 49 CFR 171.8). Single packagings are generally recommended for solids meeting the definition of form Number 2 or Form Number 3, or gases. For packaging of solids $\mathrm{classed}$ as Form Number 1 and liquids, composite or combination packagings are recommended.

\subsection{CONTAINMENT}

The following sections of 49 CFR pertain to containment of contents:

173.24(b) Design and construction

$173.24(\mathrm{e})(2)$ Reaction

173.24(e)(3) Plastic packagings and receptacles

173.24(f) Closures and gaskets

$173.410(i)$ Air shipments, containment and shielding - temperature range

$173.412(\mathrm{j})(1)$ Loss or dispersal

173.462(c) Containment system...specified

173.469 (a) (4) Leaktightness.

All hazardous materials packages are to have "no significant release of the hazardous materials to the environment," and the packaging must remain effective when subjected to conditions normal to transport, with account being taken for any reactions between the contents and the packaging materials. In practice "no significant release" implies no measurable leakage based on visual evaluation. A Type A packaging when subjected to the "Type A packaging tests" is expected to prevent loss or dispersal of the radioactive contents. As the radioactive material is usually simulated using a nonradioactive substitute, the ability to meet this requirement is usually based on visually looking for a sign of contents outside the test package. For gases, loss of material may be determined by pressure measurement .

For some packaging a leakage rate may be measured to a leak detection sensitivity of $1 \times 10^{-4} \mathrm{std}-\mathrm{cm}^{5} / \mathrm{s}$. In special form tests, the leakage rate shall be measured to a leak detection sensitivity of $1 \times 10^{-4}$ torr-l/s $\left(1.3 \times 10^{-4} \mathrm{~atm}-\mathrm{cm}^{3} / \mathrm{s}\right)$, based on air at $25^{\circ} \mathrm{C}\left(77^{\circ} \mathrm{F}\right)$ and one atmosphere differential presşure for solid radioactive content, or $1 \times 10^{-6}$ torr-1/s $\left(1.3 \times 10^{-6} \mathrm{~atm}-\mathrm{cm}^{3} / \mathrm{s}\right)$ for 1 iquid or gaseous radioactive content. 
Containment is formed by those materials or components that are or may be in direct contact with the contents during shipment. The design process will involve choices of basic material, use of filters or other pressure relief devices, gaskets or other seal materials, closure mechanisms, and other features. Typical containment materials are high-density polyethylene (HDPE), polypropylene, glass, and steel. The designer should review all of the design-related regulatory requirements and address them in the design process.

\subsection{SHIELDING}

The following sections of 49 CFR pertain to the design of shielding for Type A packagings:
$173.412(c)$
Temperature $\left(-40\right.$ to $70^{\circ} \mathrm{C}\left[-40\right.$ to $\left.\left.158^{\circ} \mathrm{F}\right]\right)$, brittle fracture
$173.412(\mathrm{~h})$ Shielding/containment interface
$173.412(j)(2)$
173.441

\author{
Significant increase in radiation levels \\ Radiation level limitations.
}

Shielding may be required for Type A quantities of radionuclides. Lead or steel are commonly used materials for shielding. The regulations require the shielding (if used), and containment systems of the packaging remain effective when subjected to normal conditions of transport.

When evaluated against the performance requirements and tests specified in $\$ 173.465$ or using any of the methods authorized by $\$ 173.461(\mathrm{a})$, the packaging will prevent a significant increase in the radiation levels recorded or calculated at the external surfaces for the condition before the test. A significant increase may be defined as, "Loss of shielding integrity which would result in more than a 20 percent increase in the radiation level at any external surface of the package" (IAEA 1985).

\subsection{LIFTING AND HANDLING}

The following sections of 49 CFR pertain to the design of lifting and handling features of Type $A$ packagings:

173.410(a) Handling, securing

173.410 (b) Lifting attachments .

The exterior design of the packaging shall meet the above requirements. Analysis shall be provided to document that lifting attachments comply with 173.410(b), see Section 3.1, Design Documentation. 


$$
\text { WHC-SD-TP-RPT-017 }
$$

Revision 1

\subsection{TIEDOWN}

The following sections of 49 CFR pertain to the design of tie down features of Type A packagings:

$$
\begin{array}{ll}
173.410(a) & \text { Handling, securing } \\
173.412(i) & \text { Tiedown, failure. }
\end{array}
$$

Package tie down features and equipment shall meet the above requirements.

\subsection{PACKAGING OPERATIONS}

\subsection{GENERAL}

The operating instructions for a packaging are the primary vehicle for the shipper to maintain control on the assembly, loading, and closure processes for a packaging and its preparation for shipment and other items. Accordingly, the applicant is requested to prepare an operating instruction for the packaging system and forward it along with the design documentation as discussed above.

\subsection{OPERATING INSTRUCTION}

The operating instruction shall consist of the following primary sections:

- Packaging description

- Authorized contents

- Preloading inspections

- Loading procedure

- Preparation for shipment

- Preshipment inspections

- Shipment requirements

- Unloading procedure

- Reuse/reconditioning (if applicable).

The packaging description and authorized contents sections shall be similar to the material for a packaging included in WHC-EP-0558, Test and 
WHC-SD-TP-RPT-017

Revision 1

Evaluation Document for DOT Specification 7A Type A Packaging (Cruse 1992).

The applicant shall determine the preloading inspections to be performed and the acceptance criteria considered necessary to ensure that the packaging complies with the design [49 CFR 173.474]. The loading procedure shall address all operations necessary to correctly assemble the packaging components, load the contents, and close the packaging [49 CFR 178.2(c)]. This procedure will be followed when preparing the package (with simulated contents) for testing.

The procedure addressing preparation for shipment should meet labeling and placarding requirements (see 49 CFR, Part 172, Subpart E and Subpart F) and any other applicable requirements. If the packaging must be secured to the conveyance in a particular fashion, this should also be specified in a section to be entitled "Tiedown."

The document should be an applicant-controlled document with the number, revision, and date printed on each page.

The procedure addressing preshipment inspections shall require documentation of verifications for compliance with the following requirements:

173.441 Radiation leve1 limitations

173.442 Thermal limitations

173.443 Contamination control

173.474 Quality control for construction of packaging

173.475 Quality control requirements prior to each shipment of radioactive materials.

The section addressing shipment requirements shall meet the requirements and procedures applicable when the package is en route to its destination. For example, the requirements of 49 CFR 173.447 , storage incident to transportation, shall be addressed in this section.

The unloading procedure shall detail all steps necessary to safely unload the package from the conveyance and for unloading the contents from the packaging.

If the packaging may be reused, then the operating instruction shall include procedures for reconditioning the packaging to a state that will meet the design requirements, as established in the drawing and specification. The procedure shall require documented inspection of the condition of the packaging. 
WHC-SD-TP-RPT-017

Revision 1

\subsection{PACKAGING QUALIFICATION CHECKLIST}

Appendix B contains the PQCL. Upon completion of the items discussed herein involving design documentation and operating instructions, the applicant is requested to complete the $\mathrm{PQCL}$ and forward it along with copies of the documentation to the DOE-approved test facility. The name and address of the test facility will be provided by the DOE when the docket is opened. It is recommended that packaging developers not using the DOE DOT-7A Program to qualify their package use the PQCL as a checklist to verify the applicable Type A packaging requirements are met.

\subsection{PREPARATIONS FOR TESTING}

Upon receipt of the documentation package from the applicant, the DOEapproved test facility will review this information and resolve any comments with the applicant. Testing may begin during or after this process at the discretion of the DOE-approved test facility. The applicant will generally be responsible for preparation of test unit packages for testing, and for delivering them to the DOE-approved test facility. For planning purposes, a minimum of three test units are usually required per package configuration to serve the testing needs. More units are normally required, the number depending on the packaging design. The DOE- approved test facility will inform applicants of the total number of test units required as soon as possible.

Proof testing, on behalf of the sponsor, may be required by the DOEapproved test facility prior to actual testing.

\subsection{PROOF TESTING}

Potential problems are never truly known; they can only be anticipated. In anticipation of possible problems, the DOE-approved test facility may request the sponsor to reveal any proof testing they may have conducted. During the design review, if a feature important to safety, with no history of use is revealed, proof testing of the feature may be requested. Test sponsors planning to proof test packagings are encouraged to work directly with the DOE-approved test facility in developing the best test sequence. The test facility will make recommendations to ensure the proof testing adequately represents the forces to be seen by the containment and shielding during actual testing. Remember, the purpose of the proof testing is to ensure that the packaging, when subjected to the DOT-required testing, provides containment, with no release of contents. Also, any increase in radiation levels are to be insignificant (less than 20 percent). 


\subsubsection{Considerations - Water Spray Test}

The water spray test must precede each test or test sequence as described in 49 CFR 173.465. It is important that the exterior of the packaging materials are durable enough to withstand any degradation that may occur during Type A testing, without loss of contents or a significant increase in the radiation levels. In addition to the free drop test described in 49 CFR $173.465(\mathrm{c})$, fiberboard and wood packages require additional testing.

As required by 49 CFR 173.465(c)(3), fiberboard or wood rectangular packages, not exceeding $50 \mathrm{~kg}(110 \mathrm{lb})$ in weight, shall have a separate packaging subjected to a free drop onto each corner from a height of $0.3 \mathrm{~m}$ $(1 \mathrm{ft})$. For fiberboard cylindrical packages weighing not more than $100 \mathrm{~kg}$ (220 1b), 49 CFR 173.465(c)(4) requires that a separate specimen be subjected to a free drop onto each of the quarters of each rim from a height of $0.3 \mathrm{~m}$ $(1 \mathrm{ft})$. Here, it becomes extremely important that the packaging designer be aware of the requirements, and that the integrity of the materials of construction be well known.

\subsubsection{Considerations - Reduced Pressure Test}

Another important design consideration is in the area of reduction of ambient (external) pressure. Per 49 CFR 173.412(f), the containment system must retain its radioactive contents under the reduction of ambient pressure to $25 \mathrm{kPa}$ ( $3.6 \mathrm{psi}$ ).

The reduced pressure test simulates the reduction of external pressure to the package to $25 \mathrm{kPa}(3.6 \mathrm{psi})$. This may be achieved by pressurizing the internal cavity of the packaging to $78.0 \mathrm{kPa}$ (11.3 psig), or by placing an empty but closed packaging into a chamber that can be evacuated to $25 \mathrm{kPa}$ (3.6 psia). In both cases, leak detection by visual identification of loss of material, gas pressure drop, gas bubble, soap bubble, or other method sensitive to $10 \mathrm{E}^{-03}$ std-cc/sec will typically be used. 


\section{WHC-SD-TP-RPT-B17 \\ Revision 1}

\subsection{REFERENCIES}

49 CFR, "Transportation," Parts 100 to 177 and Parts 178 to 199, Code of Federal Regulations, as amended.

ANSI, 1982, American National Standard for Dimensioning and Tolerancing, ANSI Standard Y14.5M-(1982), American National Standards Institute, New York, New York.

Cruse, J. M., 1992, Test and Evaluation Document for DOT Specification $7 A$ Type A Packaging, WHC-EP-0558, Revision 3, Westinghouse Hanford Company, Richland, Washington.

HM-181, 1990, Federal Register, Part II, Department of Transportation, Research and Special Programs Administration, Vol. 55, No. 246, Rules and Regulations, Docket No. HM-181, dated December 21, 1990.

HM-169A, 1995, Federal Register, Part III, Department of Transportation, Research and Special Programs Administration, Vol. 60, No. 188, Rules and Regulations, Docket No. HM-169A, dated September 28, 1995.

IAEA, 1985, IAEA Safety Standards, Safety Series No. 6, Regulations for the Safe Transport of Radioactive Material, 1985 Edition, International Atomic Energy Agency, Vienna, Austria.

NRC, 1984, Information Notice 84-72, dated September 10, 1984, Nuclear Regulatory Commission, Office of Inspection and Enforcement.

\subsection{GLOSSARY}

CFR Code of Federal Regulations

DOE U.S. Department of Energy

DOE-HQ U.S. Department of Energy-Headquarters

DOT U.S. Department of Transportation

DOT-7A U.S. Department of Transportation Specification 7A Type A

EM-76 Office of Transportation, Emergency Management, and Analytical Services (DOE-HQ)

HDPE high-density polyethylene

ICAO International Civil Aviation Organization

LSA low specific activity

NRC U.S. Nuclear Regulatory Commission

POP Performance-0riented Packagings

PQCL Packaging Qualification Checklist

STP standard temperature and pressure

UN United Nations

WHC Westinghouse Hanford Company 
WHC-SD-TP-RPT-1017

Revision 1

APPENDIX A

TITLE 49 CODE OF FEDERAL REGULATIONS EXCERPTS

A-1 
WHC-SD-TP-RPT-D17

Revision 1

\section{A.1 TITLE 49 CFR 173.24, GENERAL REQUIREMENTS FOR PACKAGINGS AND PACKAGES}

(a) Applicability. Except as otherwise provided in this subchapter, the provisions of this section apply to--

(1) Bulk and non-bulk packagings;

(2) New packagings and packagings which are reused; and

(3) Specification and non-specification packagings.

(b) Each package used for shipment of hazardous materials under this subchapter shall be designed, constructed, maintained, filled, its contents so limited, and closed so that under conditions normally incident to transportation--

(1) Except as otherwise provided in this subchapter, there will be no identifiable (without the use of instruments) release of hazardous materials to the environment;

(2) The effectiveness of the package will not be substantially reduced; for example, impact resistance, strength, packaging compatibility, etc. must be maintained for the minimum and maximum temperatures encountered during transportation;

(3) There will be no mixture of gases or vapors in the package which could, through any credible spontaneous increase of heat or pressure, significantly reduce the effectiveness of the packaging.

(c) Authorized packagings. A packaging is authorized for a hazardous material only if--

(1) The packaging is prescribed or permitted for the hazardous material in a packaging section specified for that material in Column 8 of the $\$ 172.101$ Table and conforms to applicable requirements in the special provisions of Column 7 of the $\$ 172.101$ Table and, for specification packagings (but not including UN standard packagings manufactured outside the United States), the specification requirements in parts 178 and 179 of this subchapter; or

(2) The packaging is permitted under, and conforms to, provisions contained in $\S \S 171.11,171.12,171.12 \mathrm{a}, 173.3,173.4,173.5,173.7$, 173.27 , or 176.11 of this subchapter.

(d) Specification packagings and UN standard packagings manufactured outside the U.S.--

(1) Specification packagings. A specification packaging, including a UN standard packaging manufactured in the United States, must conform in all details to the applicable specification or standard in part 178 or part 179 of this subchapter.

(2) UN standard packagings manufactured outside the United States. A UN standard packaging manufactured outside the United States, in accordance with national or international regulations based on the UN Recommendations on the Transport of Dangerous Goods, may be imported and used and is considered to be an authorized packaging under the provisions of paragraph (c)(1) of this section, subject to the following conditions and limitations: 
WHC-SD-TP-RPT-017

Revision 1

(i) The packaging fully conforms to applicable provisions in the UN Recommendations on the Transport of Dangerous Goods and the requirements of this subpart, including reuse provisions;

(ii) The packaging is capable of passing the prescribed tests in part 178 of this subchapter applicable to that standard; and

(iii) The competent authority of the country of manufacture provides reciprocal treatment for UN standard packagings manufactured in the U.S.

(e) Compatibility.

(1) Even though certain packagings are specified in this part, it is, nevertheless, the responsibility of the person offering a hazardous material for transportation to ensure that such packagings are compatible with their lading. This particularly applies to corrosivity, permeability, softening, premature aging and embrittlement.

(2) Packaging materials and contents must be such that there wi11 be no significant chemical or galvanic reaction between the materials and contents of the package.

(3) Plastic packagings and receptacles.

(i) Plastic used in packagings and receptacles must be of a type compatible with the lading and may not be permeable to an extent that a hazardous condition is likely to occur during transportation, handling or refilling.

(ii) Each plastic packaging or receptacle which is used for liquid hazardous materials must be capable of withstanding without failure the procedure specified in Appendix B of this part ("Procedure for Testing Chemical Compatibility and Rate of Permeation in Plastic Packagings and Receptacles"). The procedure specified in Appendix B of this part must be performed on each plastic packaging or receptacle used for Packing Group I materials. The maximum rate of permeation of hazardous lading through or into the plastic packaging or receptacles may not exceed 0.5 percent for materials meeting the definition of a Division 6.1 material according to $\$ 173.132$ and 2.0 percent for other hazardous materials, when subjected to a temperature no lower than--

(A) $18^{\circ} \mathrm{C}\left(64^{\circ} \mathrm{F}\right)$ for 180 days in accordance with Test Method 1 in Appendix $B$ of this part;

(B) $50^{\circ} \mathrm{C}\left(122^{\circ} \mathrm{F}\right)$ for 28 days in accordance with Test Method 2 in Appendix $B$ of this part; or

(C) $60^{\circ} \mathrm{C}\left(140^{\circ} \mathrm{F}\right)$ for 14 days in accordance with Test Method 3 in Appendix B of this part.

(iii) Alternative procedures or rates of permeation are permitted if they yield a level of safety equivalent to or greater than that provided by paragraph (e)(3)( $i$ i) of this section and are specifically approved by the Associate Administrator for Hazardous Materials Safety.

(4) Mixed contents. Hazardous materials may not be packed or mixed together in the same outer packaging with other hazardous or 
WHC-SD-TP-RPT-D17

Revision 1

nonhazardous materials if such materials are capable of reacting dangerous $7 y$ with each other and causing--

(i) Combustion or dangerous evolution of heat;

(ii) Evolution of flammable, poisonous, or asphyxiant gases; or

(iii) Formation of unstable or corrosive materials.

(5) Packagings used for solids, which may become liquid at

temperatures likely to be encountered during transportation, must be

capable of containing the hazardous material in the liquid state.

(f) Closures.

(1) Closures on packagings shall be so designed and closed that under conditions (including the effects of temperature and

vibration) normally incident to transportation--

(i) Except as provided in paragraph ( $g$ ) of this section, there is no identifiable release of hazardous materials to the environment from the opening to which the closure is applied; and

(ii) The closure is secure and leakproof.

(2) Except as otherwise provided in this subchapter, a closure (including gaskets or other closure components, if any) used on a specification packaging must conform to all applicable requirements of the specification.

(g) Venting. Venting of packagings, to reduce internal pressure which may develop by the evolution of gas from the contents, is permitted only when--

(1) Transportation by aircraft is not involved;

(2) Except as otherwise provided in this subchapter, the evolved gases are not poisonous, likely to create a flammable mixture with air or be an asphyxiant under normal conditions of transportation; (3) The packaging is designed so as to preclude an unintentional release of hazardous materials from the receptacle; and

(4) For shipments in bulk packagings, venting is authorized for the specific hazardous material by a special provision in the $\$ 172.101$ Table or by the applicable bulk packaging specification in part 178 of this subchapter.

(h) Outage and filling 1 imits--

(1) General. When filling packagings and receptacles for liquids, sufficient ullage (outage) must be left to ensure that neither leakage nor permanent distortion of the packaging or receptacle will occur as a result of an expansion of the liquid caused by temperatures likely to be encountered during transportation. Requirements for outage and filling limits for non-bulk and bulk packaging are specified in $\$ \$ 173.24 \mathrm{a}(\mathrm{d})$ and $173.24 \mathrm{~b}(\mathrm{a})$, respectively.

(2) Compressed gases and cryogenic liquids. Filling limits for compressed gases and cryogenic liquids are specified in $\$ \S 173.301$ through 173.306 for cylinders and $\$ \$ 173.314$ through 173.319 for bulk packagings. 
WHC-SD-TP-RPT-017

Revision 1

(i) Air transportation. Packages offered or intended for transportation by aircraft must conform to the general requirements for transportation by aircraft in $\$ 173.27$, except as provided in $\$ 171.11$ of this subchapter.

\section{A.2 TITLE 49 CFR 173.24a, ADDITIONAL GENERAL REQUIREMENTS FOR NON-BULK PACKAGINGS AND PACKAGES}

(a) Packaging design. Except as provided in $\$ 172.312$ of this subchapter:

(1) Inner packaging closures. A combination packaging containing liquid hazardous materials must be packed so that closures on inner packagings are upright.

(2) Friction. The nature and thickness of the outer packaging must be such that friction during transportation is not likely to generate an amount of heat sufficient to alter dangerously the chemical stability of the contents.

(3) Securing and cushioning. Inner packagings of combination packagings must be so packed, secured and cushioned to prevent their breakage or leakage and to control their movement within the outer packaging under conditions normally incident to transportation. Cushioning material must not be capable of reacting dangerously with the contents of the inner packagings.

(4) Metallic devices. Nails, staples and other metallic devices shall not protrude into the interior of the outer packaging in such a manner as to be likely to damage inner packagings or receptacles. (5) Vibration. Each non-bulk package must be capable of withstanding, without rupture or leakage, the vibration test procedure specified in $\$ 178.608$ of this subchapter.

(b) Non-bulk packaging filling limits.

(1) A single or composite non-bulk packaging may be filled with a 1 iquid hazardous material only when the specific gravity of the material does not exceed that marked on the packaging, or a specific gravity of 1.2 if not marked, except as follows:

(i) A Packing Group I packaging may be used for a Packing Group II material with a specific gravity not exceeding the greater of 1.8, or 1.5 times the specific gravity marked on the packaging, provided all the performance criteria can still be met with the higher specific gravity material;

(ii) A Packing Group I packaging may be used for a Packing Group II material with a specific gravity not exceeding the greater of 2.7 , or 2.25 times the specific gravity marked on the packaging, provided all the performance criteria can still be met with the higher specific gravity material; and

(iii) A Packing Group II packaging may be used for a Packing Group III material with a specific gravity not exceeding the greater of 
WHC-SD-TP-RPT-017

Revision 1

1.8 , or 1.5 times the specific gravity marked on the packaging, provided all the performance criteria can still be met with the higher specific gravity material.

(2) Except as otherwise provided in this section, a single or composite non-bulk packaging may not be filled with a solid hazardous material to a gross mass greater than the maximum gross mass marked on the packaging.

(3) A single or composite non-bulk packaging which is tested and marked for liquid hazardous materials may be filled with a solid hazardous material to a gross mass, in kilograms, not exceeding the rated capacity of the packaging in liters, multiplied by the specific gravity marked on the packaging, or 1.2 if not marked. In addition:

(i) A single or composite non-bulk packaging which is tested and marked for Packing Group I liquid hazardous materials may be filled with a solid Packing Group II hazardous material to a gross mass, in kilograms, not exceeding the rated capacity of the packaging in liters, multiplied by 1.5 , multiplied by the specific gravity marked on the packaging, or 1.2 if not marked.

(ii) A single or composite non-bulk packaging which is tested and marked for Packing Group I liquid hazardous materials may be filled with a solid Packing Group III hazardous material to a gross mass, in kilograms, not exceeding the rated capacity of the packaging in liters, multiplied by 2.25 , multiplied by the specific gravity marked on the packaging, or 1.2 if not marked.

(iii) A single or composite non-bulk packaging which is tested and marked for Packing Group II liquid hazardous materials may be filled with a solid Packing Group III hazardous material to a gross mass, in kilograms, not exceeding the rated capacity of the packaging in liters, multiplied by 1.5 , multiplied by the specific gravity marked on the packaging, of 1.2 if not marked.

(4) Packagings tested as prescribed in \$178.605 of this subchapter and marked with the hydrostatic test pressure as prescribed in $\S 178.503(a)(5)$ of this subchapter may be used for liquids only when the vapor pressure of the liquid conforms to one of the following:

(i) The vapor pressure must be such that the total pressure in the packaging [i.e., the vapor pressure of the liquid plus the partial pressure of air or other inert gases, less $100 \mathrm{kPa}(15 \mathrm{psi})$ at $55^{\circ} \mathrm{C}$ $\left(131^{\circ} \mathrm{F}\right)$, determined on the basis of a maximum degree of filling in accordance with paragraph (d) of this section and a filling temperature of $\left.15^{\circ} \mathrm{C}\left(59^{\circ} \mathrm{F}\right)\right]$, will not exceed two-thirds of the marked test pressure;

(ii) The vapor pressure at $50^{\circ} \mathrm{C}\left(122^{\circ} \mathrm{F}\right)$ must be less than foursevenths of the sum of the marked test pressure plus $100 \mathrm{kPa}$ (15 psi); or

(iii) The vapor pressure at $55^{\circ} \mathrm{C}\left(131^{\circ} \mathrm{F}\right)$ must be less than twothirds of the sum of the marked test pressure plus $100 \mathrm{kPa}$ (15 psi). 
WHC-SD-TP-RPT-017

Revision 1

(5) No hazardous material may remain on the outside of a package after filling.

(c) Mixed contents.

(1) An outer non-bulk packaging may contain more than one hazardous material only when--

(i) The inner and outer packagings used for each hazardous material conform to the relevant packaging sections of this part applicable to that hazardous material;

(ii) The package as prepared for shipment meets the performance tests prescribed in part 178 of this subchapter for the packing group indicating the highest order of hazard for the hazardous materials contained in the package;

(iii) Corrosive materials (except ORM-D) in bottles are further packed in securely closed inner receptacles before packing in outer packagings; and

(iv) For transportation by aircraft, the total net quantity does not exceed the lowest permitted maximum net quantity per package as shown in Column 9a or 9b, as appropriate, of the $\$ 172.101$ Table. The permitted maximum net quantity must be calculated in kilograms if a package contains both a liquid and a solid.

(2) A packaging containing inner packagings of Division 6.2

materials may not contain other hazardous materials, except dry ice.

(d) Liquids must not completely fill a receptacle at a temperature of $55^{\circ} \mathrm{C}\left(131^{\circ} \mathrm{F}\right)$ or less.

\section{A.3 TITLE 49 CFR $173.24 \mathrm{~b}$, ADDITIONAL GENERAL REQUIREMENTS FOR BULK PACKAGINGS}

(a) Outage and filling limits.

(1) Liquids and liquefied gases must be so loaded that the outage is at least one percent of the total capacity of a cargo or portable tank, or compartment thereof, or at least one percent of the total capacity of the tank and dome for tank car and multi-unit tank car tanks at the reference temperature of $46^{\circ} \mathrm{C}\left(115^{\circ} \mathrm{F}\right)$ for uninsulated tanks and $41^{\circ} \mathrm{C}\left(105^{\circ} \mathrm{F}\right)$ for insulated tanks.

(2) Hazardous materials may not be loaded into the dome of a tank

car. If the dome of the tank car does not provide sufficient outage, vacant space must be left in the shell to provide the required outage.

(3) Bulk packagings for materials poisonous by inhalation. For a material which meets the definition of poisonous by inhalation (see $\$ 178.1$ of this subchapter), the outage in a bulk packaging must be at least five percent of the total capacity of the tank or compartment at the reference temperature of $46^{\circ} \mathrm{C}\left(115^{\circ} \mathrm{F}\right)$ for uninsulated tanks and $41^{\circ} \mathrm{C}\left(105^{\circ} \mathrm{F}\right)$ for insulated tanks. 
(b) Equivalent steel. For the purposes of this section, stainless steel is steel with a guaranteed minimum tensile strength of 51.7 deka newtons per square millimeter $(75,000 \mathrm{psi})$ and a guaranteed elongation of 40 percent or greater. Where the regulations permit steel other than stainless steel to be used in place of a specified stainless steel (for example, as in $\$ 172.102$ of this subchapter, special provision B30), the minimum thickness for the steel must be obtained from one of the following formulas, as appropriate:

\section{Formula for metric units:}

$e_{1}=\left(12.74 e_{0}\right) /\left(R m_{1} A_{1}\right)^{1 / 3}$

Formula for non-metric units:

$e_{1}=\left(144.2 e_{0}\right) /\left(R_{1} A_{1}\right)^{1 / 3}$

Where:

\footnotetext{
$\mathbf{e}_{0}=$ Required thickness of the reference stainless steel in millimeters or inches respectively;

$e_{1}=$ Equivalent thickness of the steel used in millimeters or inches respectively.

$\mathrm{Rm}_{1}=$ Specified minimum tensile strength of the steel used in deka newtons per square

millimeter or pounds per square inch respectively; and

$A_{1}=$ Specified minimm percentage elongation of the steel used multiplied by 100 (for example, 20 percent times 100 equals 20 ). Elongation values used must be determined from a $50 \mathrm{~mm}$ or 2 inch test specimen.
}

(c) Air pressure in excess of ambient atmospheric pressure may not be used to load or unload any lading which may create an air-enriched mixture within the flammability range of the lading in the vapor space of the tank.

(d) A bulk packaging may not be loaded with a hazardous material that: (1) Is at a temperature outside of the packaging's design temperature range; or

(2) Except as otherwise provided in this subchapter, exceeds the maximum weight of lading marked on the specification plate.

\section{A.4 TITLE 49 CFR 173.410, GENERAL DESIGN REQUIREMENTS}

In addition to the requirements of subparts $A$ and $B$ of this part, each package used for the shipment of Class 7 (radioactive) materials must be designed so that--

(a) The package can be easily handled and properly secured in or on a conveyance during transport.

(b) Each lifting attachment that is a structural part of the package must be designed with a minimum safety factor of three against yielding when used to lift the package in the intended manner, and it must be 
WHC-SD-TP-RPT-017

Revision 1

designed so that failure of any lifting attachment under excessive load would not impair the ability of the package to meet other requirements of this subpart. Any other structural part of the package which could be used to lift the package must be capable of being rendered inoperable for 1 ifting the package during transport or must be designed with strength equivalent to that required for lifting attachments.

(c) The external surface, as far as practicable, will be free from protruding features and will be easily decontaminated.

(d) The outer layer of packaging will avoid, as far as practicable, pockets or crevices where water might collect.

(e) Each feature that is added to the package will not reduce the safety of the package.

(f) The package will be capable of withstanding the effects of any acceleration, vibration or vibration resonance that may arise under normal conditions of transport without any deterioration in the effectiveness of the closing devices on the various receptacles or in the integrity of the package as a whole and without loosening or unintentionally releasing the nuts, bolts, or other securing devices even after repeated use (see $\$ \$ 173.24,173.24 a$, and 173.24b).

(g) The materials of construction of the packaging and any components or structure will be physically and chemically compatible with each other and with the package contents. The behavior of the packaging and the package contents under irradiation will be taken into account.

(h) All valves through which the package contents could escape will be protected against unauthorized operation;

(i) For transport by air--

(1) The temperature of the accessible surfaces of the package will not exceed $50^{\circ} \mathrm{C}\left(122^{\circ} \mathrm{F}\right)$ at an ambient temperature of $38^{\circ} \mathrm{C}\left(100^{\circ} \mathrm{F}\right)$ with no account taken for insulation;

(2) The integrity of containment will not be impaired if the package is exposed to ambient temperatures ranging from $-40^{\circ} \mathrm{C}\left(-40^{\circ} \mathrm{F}\right)$ to $+55^{\circ} \mathrm{C}\left(131^{\circ} \mathrm{F}\right)$; and

(3) Packages containing liquid contents will be capable of withstanding, without leakage, an internal pressure that produces a pressure differential of not less than $95 \mathrm{kPa}\left(13.8 \mathrm{lb} / \mathrm{in}^{2}\right)$.

\section{A.5 TITLE 49 CFR 173.412 , ADDITIONAL DESIGN REQUIREMENTS FOR TYPE A PACKAGES}

In addition to meeting the general design requirements prescribed in $\$ 173.410$, each Type A packaging must be designed so that--

(a) The outside of the packaging incorporates a feature, such as a seal, that is not readily breakable, and that, while intact, is evidence that the package has not been opened. In the case of packages shipped in closed transport vehicles in exclusive use, the cargo compartment, instead of the individual packages, may be sealed. 
WHC-SD-TP-RPT-D17

Revision 1

(b) The smallest external dimension of the package is not less than 10 cent imeters (4 inches).

(c) Containment and shielding is maintained during transportation and storage in a temperature range of $-40^{\circ} \mathrm{C}\left(-40^{\circ} \mathrm{F}\right)$ to $70^{\circ} \mathrm{C}\left(158^{\circ} \mathrm{F}\right)$.

Special attention shall be given to 1 iquid contents and to the potential degradation of the packaging materials within the temperature range.

(d) The packaging must include a containment system securely closed by a positive fastening device that cannot be opened unintentionally or by pressure that may arise within the package during normal transport. Special form Class 7 (radioactive) material, as demonstrated in accordance with $\$ 173.469$, may be considered as a component of the containment system. If the containment system forms a separate unit of the package, it must be securely closed by a positive fastening device that is independent of any other part of the package.

(e) For each component of the containment system account is taken, where applicable, of radiolytic decomposition of materials and the generation of gas by chemical reaction and radiolysis.

(f) The containment system will retain its radioactive contents under the reduction of ambient pressure to $25 \mathrm{kPa}$ ( 3.6 pounds per square inch).

(g) Each valve, other than a pressure relief device, is provided with an enclosure to retain any leakage.

(h) Any radiation shield that encloses a component of the packaging specified as part of the containment system will prevent the unintentional escape of that component from the shield.

(i) Failure of any tie-down attachment that is a structural part of the packaging, under both normal and accident conditions, must not impair the ability of the package to meet other requirements of this subpart.

(j) When evaluated against the performance requirements of this section and the tests specified in $\$ 173.465$ or using any of the methods authorized by $\$ 173.461(\mathrm{a})$, the packaging wi1l prevent--

(1) Loss or dispersal of the radioactive contents; and

(2) A significant increase in the radiation levels recorded or calculated at the external surfaces for the condition before the test.

(k) Each packaging designed for liquids will--

(1) Be designed to provide for ullage to accommodate variations in temperature of the contents, dynamic effects and filling dynamics;

(2) Meet the conditions prescribed in paragraph $(j)$ of this section when subjected to the tests specified in $\$ 173.466$ or evaluated against these tests by any of the methods authorized by $\$ 173.461(\mathrm{a})$; and

(3) Either--

(i) Have sufficient suitable absorbent material to absorb twice the volume of the liquid contents. The absorbent material must be compatible with the package contents and suitably positioned to contact the 1 iquid in the event of leakage; or 


$$
\text { WHC-SD-TP-RPT-017 }
$$

Revision 1

(ii) Have a containment system composed of primary inner and secondary outer containment components designed to assure retention of the liquid contents within the secondary outer component in the event that the primary inner component leaks.

(1) Each package designed for gases, other than tritium not exceeding 40 TBq $(1000 \mathrm{Ci})$ or noble gases not exceeding the $A_{2}$ value appropriate for the noble gas, will be able to prevent loss or dispersal of contents when the package is subjected to the tests prescribed in $\$ 173.466$ or evaluated against these tests by any of the methods authorized by $\S 173.461(\mathrm{a})$.

\section{A.6 TITLE 49 CFR 173.462 , PREPARATION OF SPECIMENS FOR TESTING}

(a) Each specimen (i.e., sample, prototype or scale model) must be examined before testing to identify and record faults or damage, including:

(1) Divergence from the specifications or drawings;

(2) Defects in construction;

(3) Corrosion or other deterioration; and

(4) Distortion of features.

(b) Any deviation found under paragraph (a) of this section from the specified design must be corrected or appropriately taken into account in the subsequent evaluation.

(c) The containment system of the packaging must be clearly specified.

(d) The external features of the specimen must be clearly identified so that reference may be made to any part of it.

\section{A.7 TITLE 49 CFR 178.2, APPLICABILITY AND RESPONSIBILITY}

(a) Applicability.

(1) The requirements of this part apply to packagings manufactured--

(i) To a DOT specification, regardless of country of manufacture; or

(ii) To a UN standard, for packagings manufactured within the United States. For UN standard packagings manufactured outside the United States, see $\$ 173.24$ (d) (2) of this subchapter. For UN standard packagings for which standards are not prescribed in this part, see \$178.3(b).

(2) A manufacturer of a packaging subject to the requirements of this part is primarily responsible for compliance with the requirements of this part. However, any person who performs a function prescribed in this part shall perform that function in accordance with this part. 
WHC-SD-TP-RPT-017

Revision 1

(b) Specification markings. When this part requires that a packaging be marked with a DOT specification or UN standard marking, marking of the packaging with the appropriate DOT or UN markings is the certification that--

(1) Except as otherwise provided in this section, all requirements of the DOT specification or UN standard, including performance tests, are met; and

(2) All functions performed by, or on behalf of, the person whose name or symbol appears as part of the marking conform to requirements specified in this part.

(c) Notification. Except as specifically provided in \$\$178.337-18 and 178.345-10 of this part, the manufacturer or other person certifying compliance with the requirements of this part, and each subsequent distributor of that packaging shall--

(1) Notify in writing each person to whom that packaging is transferred--

(i) Of all requirements in this part not met at the time of transfer, and

(ii) of the type and dimensions of any closures, including gaskets, needed to satisfy performance test requirements.

(2) Retain copies of each written notification for at least one

year from date of issuance; and

(3) Make copies of all written notifications available for inspection by a representative of the Department.

(d) Except as provided in paragraph (c) of this section, a packaging not conforming to the applicable specifications or standards in this part may not be marked to indicate such conformance.

(e) Definitions. For the purpose of this part--

Manufacturer means the person whose name and address or symbol appears as part of the specification markings required by this part or, for a packaging marked with the symbol of an approval agency, the person on whose behalf the approval agency certifies the packaging.

Specification markings mean the packaging identification markings required by this part including, where applicable, the name and address or symbol of the packaging manufacturer of approval agency.

\section{A.8 TITLE 49 CFR 178.3 , MARKING OF PACKAGINGS}

(a) Each packaging represented as manufactured to a DOT specification or a UN Standard must be marked with specification markings conforming to the applicable specification, and with the following:

(1) In an unobstructed area, with letters, and numerals identifying the standards or specification (e.g., UN IAl, DOT 4B240ET, etc.). (2) Unless otherwise specified in this part, with the name and address or symbol of the packaging manufacturer or, where specifically authorized, the symbol of the approval agency 
WHC-SD-TP-RPT-017

Revision 1

certifying compliance with a UN standard. Symbols, if used, must be registered with the Associate Administrator for Hazardous Materials Safety. Duplicative symbols are not authorized.

(3) The markings must be stamped, embossed, burned, printed or otherwise marked on the packaging to provide adequate accessibility, permanency, contrast, and legibility so as to be readily apparent and understood.

(4) Unless otherwise specified, letters and numerals must be at least $12.0 \mathrm{~mm}$ ( 0.47 inches) in height except that for packagings of less than or equal to $30 \mathrm{~L}$ ( 7.9 gallons) capacity for 7 iquids or $30 \mathrm{~kg}$ ( 66 pounds) capacity for solids the height must be at least $6.0 \mathrm{~mm}$ ( 0.2 inches). For packagings having a capacity of $5 \mathrm{~L}$ (1 gallon) or $5 \mathrm{~kg}$ (11 pounds) or less, letters and numerals must be of an appropriate size.

(5) For packages with a gross mass of more than $30 \mathrm{~kg}$ ( 66 pounds), the markings or a duplicate thereof must appear on the top or on a side of the packaging.

(b) A UN standard packaging for which the UN standard is set forth in this part may be marked with the United Nations symbol and other specification markings only if it fully conforms to the requirements of this part. A UN standard packaging for which the UN standard is not set forth in this part may be marked with the United Nations symbol and other specification markings for that standard as provided in the ICAO Technical Instructions or Annex 1 of the IMDG Code subject to the following conditions:

(1) The U.S. manufacturer must establish that the packaging conforms to the applicable provisions of the ICAO Technical Instructions or Annex 1 of the IMDG Code, respectively.

(2) If an indication of the name of the manufacturer or other identification of the packaging as specified by the competent authority is required, the name and address or symbol of the manufacturer or the approval agency certifying compliance with the UN standard must be entered. Symbols, if used, must be registered with the Associate Administrator for Hazardous Materials Safety. (3) The letters "USA" must be used to indicate the State authorizing the allocation of the specification marks if the packaging is manufactured in the United States.

(c) Where a packaging conforms to more than one UN standard or DOT specification, the packaging may bear more than one marking, provided the packaging meets all the requirements of each standard or specification. Where more than one marking appears on a packaging, each marking must appear in its entirety. 


\section{WHC-SD-TP-RPT-017}

Revision 1

\section{ALSO SEE:}

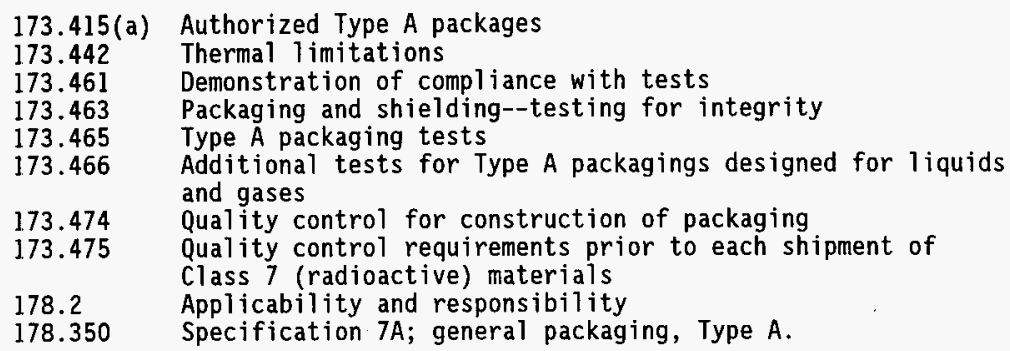


WHC-SD-TP-RPT-017

Revision 1

\section{APPENDIX B}

DOT-7A TYPE A

PACKAGING QUALIFICATION CHECKLIST

B-1 
When subjected to the tests specified in 49 CFR 173.465 (and 173.466 when applicable) or evaluated against these tests by any of the methods authorized by 49 CFR 173.461(a), the packaging will prevent:

(1) Loss or dispersal of the radioactive contents; and

(2) Any significant increase in the radiation levels recorded or calculated at the external surfaces for the condition before the test.

\subsection{Characterization of Contents}

\section{Radiological}

Limited to Type A Quantity of Radionuclides

Isotopic Inventory:

\begin{tabular}{|l|l|l|l|l|l|}
\hline \multirow{2}{*}{ RADIONUCLIDES } & \multicolumn{2}{|c|}{ QUANTITY (per package) } & DECAY HEAT \\
\cline { 2 - 6 } & Curies & Grams & $\begin{array}{r}\text { Grams } \\
\text { Fissile }\end{array}$ & Watts/gram \\
\hline & & & & & \\
\hline & & & & \\
\hline & & & & \\
\hline
\end{tabular}

(Use extra sheets if needed.)
Fissile Class:
[ ]-Exempt
[ ]-Fissile

Physical

Form Category:

[ ] Normal

[ ] Special (see 49 CFR 173.469)

Physical Form:

[ ] Solid

[ ] Form 1 [ ] Form 2 [ ] Form 3

Density: $\left(\mathrm{kg} / \mathrm{m}^{3}\right)$

[ ] Liquid

Specific gravity:

Viscosity:

[ ] Gas

Volume : $\left(\mathrm{cm}^{3}\right.$ at STP)

Therma 1

Total wattage of contents: (watts/package) 


\subsection{Characterization of Contents (continued)}

\section{Chemical}

Non-Radioactive Constituents:

\begin{tabular}{|c|c|c|c|c|}
\hline \multirow[t]{2}{*}{ PROPER SHIPPING NAME } & \multirow[t]{2}{*}{$\begin{array}{c}\text { IDENT IFICATION } \\
\text { NUMBER }\end{array}$} & \multicolumn{3}{|c|}{$\begin{array}{l}\text { EXPECTED QUANTITY } \\
\text { (per package) }\end{array}$} \\
\hline & & $\begin{array}{c}\text { Sol ids } \\
\text { (grams) } \\
\end{array}$ & $\begin{array}{c}\text { Liquids } \\
\text { (ml) }\end{array}$ & $\left(\mathrm{cm}^{3}{ }^{\text {Gases }}\right.$ at STP $)$ \\
\hline & & & & \\
\hline & & & & \\
\hline & & & & \\
\hline & & & & \\
\hline & & & & \\
\hline & & & & \\
\hline & & & & \\
\hline & & & & \\
\hline & & & & \\
\hline & & & & \\
\hline & & & & \\
\hline & & & & \\
\hline & & & & \\
\hline & & & & \\
\hline & & & & \\
\hline
\end{tabular}

(Use extra sheets if needed.) 
Docket:

\subsection{CFR 173.24 General requirements for packagings and packages.}

\subsection{4(a) Applicability.}

Except as otherwise provided in this subchapter, the provisions of this section apply to--

(1) Bulk and non-bulk packagings;

(2) New packagings and packagings which are reused; and

(3) Specification and non-specification packagings.

This requirement applies. Please indicate the following.

Addressed in:

[ ] Drawing
[ ] Specification
[ Analysis Report

[ ] Operating Instruction

[ ] Manufacturer Supplied Data

[ ] Similarity or Documented Record

Specify:

\subsection{4(b) Containment.}

Each package used for the shipment of hazardous materials under this subchapter shall be designed, constructed, maintained, filled, its contents so limitiad, and closed, so that under conditions normally incident to transportation-:

(1) Except as otherwise provided in this subchapter, there will be no identifiable (without the use of instruments) release of hazardous materials to the environment;

(2) The effectiveness of the package will not be substantially reduced; for example,

impact resistance, strength, packaging compatibility, etc. must be maintained for the minimum and maximum temperatures encountered during transportation:

(3) There will be no mixture of gases or vapors in the package which could, through any

credible spontaneous increase of heat or pressure, significantly reduce the effectiveness

of the packaging.

This requirement: [ ] Does not apply.

Addressed in:

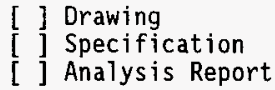

[ ] Applies; indicate the following.

[ ] Operating Instruction

[ ] Manufacturer Supplied Data

[ ] Similarity or Documented Record

Specify: 


\subsection{4(c) Authorized Packagings.}

A packaging is authorized for a hazardous material only if--

(1) The packaging is prescribed or permitted for the hazardous materiat in a packaging section specified for that material in column 8 of the $\$ 172.101$ Table and conforms to applicable requirements in the special provisions of Column 7 of the $\$ 172.101 \mathrm{Table}$ and, for specification packagings (but not including UN standard packagings manufactured outside the United States), the specification requirements in parts 178 and 179 of this subchapter; or

(2) The packaging is permitted under, and conforms to, provisions contained in $\$ \S 171.11$, $171.12,171.12 a, 173.3,173.4,173.5,173.7,173.27$ or 176.11 of this subchapter.

This requirement: [ ] Does not apply. Addressed in:
[ ] Applies; indicate the following.

[ ] Operating Instruction [ ] Manufacturer Supplied Data

[ ] Similarity or Documented Record

Specify:

\subsection{4(d)(1) Specification Packagings and UN Standard Packagings}

\section{Manufactured Outside the U.S.--}

(1) Specification packagings. A specification packaging, including a UN standard packaging manufactured in the United States, must conform in all details to the applicable specification or standard in part 178 or part 179 of this subchapter.

This requirement: [ ] Does not apply. [ ] Applies; indicate the following.

Addressed in:

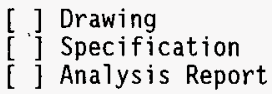

[ ] Operating Instruction

[ ] Manufacturer Supplied Data

[ ] Similarity or Documented Record

Specify: 


\subsection{4(d)(2) Specification Packagings and UN Standard Packagings Manufactured Outside the U.S.--}

(2) UN standard packagings manufactured outside the United States. A UN standard packaging, manufactured outside the United States, in accordance with national or international regulations based on the UN Recommendations of the Transport of Dangerous Goods, may be imported and used and is considered to be an authorized packaging under the provisions of paragraph (c)(1) of this section, subject to the following conditions and limitations:

(i) The packaging fully conforms to applicable provisions in the UN Recommendations on the Transport of Dangerous Goods and the requirements of this subpart, including reuse provisions;

(ii) The packaging is capable of passing the prescribed tests in part 178 of this subchapter applicable to that standard; and

(iii) The competent authority of the country of manufacture provides reciprocal treatment for UN standard packagings manufactured in the U.S.

This requirement: [ ] Does not apply. Addressed in: [ ] Drawing
[ ] Specification
[ ] Analysis Report
[ ] Applies; indicate the following.

[ ] Operating Instruction

[ ] Manufacturer Supplied Data

[ ] Similarity or Documented Record

Specify:

\subsection{4(e) Compatibility.}

(1) Even though certain packagings are specified in this part, it is, nevertheless, the responsibility of the person offering a hazardous material for transportation to ensure that such packagings are compatible with their lading. This particularly applies to corrosivity, permeability, softening, premature aging and embrittlement.

(2) Packaging materials and contents must be such that there will be no significant chemical or gatvanic reaction between the materials and contents of the package.

This requirement: [ ] Does not apply. Addressed in:

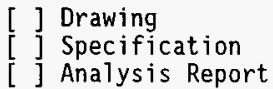

[ ] Applies; indicate the following.

[ ] Operating Instruction

[ ] Manufacturer Supplied Data

[ ] Similarity or Documented Record

Specify: 


\subsection{4(e)(3) Plastic packagings and receptacles.}

(i) Plastic used in packagings and receptacles must be of a type compatible with the lading and may not be permeable to an extent that a hazardous condition is likely to occur during transportation, handling or refilling.

(ii) Each plastic packaging or receptacle which is used for liquid hazardous materials must be capable of withstanding without failure the procedure specified in appendix $B$ of this part ("Procedure for Testing Chemical Compatibility and Rate Permeation in Plastic Packagings and Receptacles")...

This requirement: [ ] Does not apply. Addressed in:

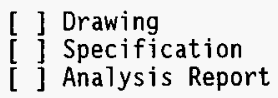

[ ] Applies; indicate the following.

[ ] Operating Instruction [ ] Manufacturer Supplied Data [ ] Similarity or Documented Record

Specify:

\subsection{4(e) Compatibility. (Continued)}

...(4) Mixed contents. Hazardous materials may not be packed or mixed together in the same outer packaging with other hazardous or nonhazardous materials if such materials are capable of reacting dangerously with each other and causing--

(i) Combustion or dangerous evolution of heat:

(ii) Evolution of flammable, poisonous, or asphyxiant gases; or

(iii) Formation of unstable or corrosive materials.

(5) Packagings used for solids, which may become liquid at temperatures likely to be encountered during transportation, must be capable of containing the hazardous material in the liquid state.

This requirement: [ ] Does not apply. Addressed in:
[ ] Applies; indicate the following.

[ ] Operating Instruction

[ ] Manufacturer Supplied Data [ ] Similarity or Documented Record

Specify: 


\section{$173.24(f)$ Closures.}

(1) Closures on packagings shall be so designed and closed that under conditions (including the effects of temperature and vibration) normally incident to transportation--

(i) Except as provided in paragraph ( $g$ ) of this section, there is no identifiable release of hazardous materials to the environment from the opening to which the closure is applied; and

(ii) The closure is secure and leakproof.

(2) Except as otherwise provided in this subchapter, a closure (including gaskets or other closure components, if any) used on a specification packaging must conform to all applicable requirements of the specification.

This requirement: [ ] Does not apply. Addressed in:

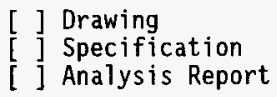

[ ] Applies; indicate the following.

[ ] Operating Instruction

[ ] Manufacturer Supplied Data

[ ] Similarity or Documented Record

Specify:

\section{$173.24(g)$ Venting.}

Venting of packagings, to reduce internal pressure which may develop by the evolution of gas from the contents, is permitted only when--

(1) Transportation by aircraft is not involved;

(2) Except as otherwise provided in this subchapter, the evolved gases are not poisonous, likely to create a flammable mixture with air or be an asphyxiant under normal conditions of transportation;

(3) The packaging is designed so as to preclude an unintentional release of hazardous materials from the receptacle; and

(4) For shipments in bulk packagings, venting is authorized for the specific hazardous material by a special provision in the $\$ 172.101$ Table or by the applicable bulk packaging specification in part 178 of this subchapter.

This requirement: [ ] Does not apply.

Addressed in:
[ ] Applies; indicate the following.

[ ] Operating Instruction

[ ] Manufacturer Supplied Data

[ ] Similarity or Documented Record

Specify: 


\subsection{4(h) Outage and Filling Limits.}

(1) General. When filling packagings and receptacles for liquids, sufficient ullage (outage) must be left to ensure that neither leakage nor permanent distortion of the packaging or receptacle will occur as a result of an expansion of the liquid caused by temperatures likely to be encountered during transportation. Requirements for outage and filling limits for non-bulk and bulk packagings are specified in $\$ \$ 173.24 a(d)$ and $173.24 \mathrm{~b}(\mathrm{a})$, respectively.

(2) Compressed gases and cryogenic liquids. Filling limits for compressed gases and cryogenic liquids are specified in $\S \S 173.301$ through 173.306 for cyl inders and $\S \S 173.314$ through 173.319 for bulk packagings.

This requirement: [ ] Does not apply.

[ ] Applies; indicate the following.

Addressed in:

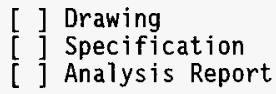

[ ] Operating Instruction
[ ] Manufacturer Supplied Data
[ ] Similarity or Documented Record

Specify:

\subsection{4(i) Air Transportation.}

Packages offered or intended for transportation by aircraft must conform to the general requirements for transportation by aircraft in $\$ 173.27$, except as provided in $\$ 171.11$ of this subchapter.

This requirement: [ ] Does not apply.

Addressed in:

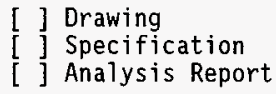

[ ] Applies; indicate the following.

[ ] Operating Instruction

[ ] Manufacturer Supplied Data

[ ] Similarity or Documented Record

Specify: 


\subsection{CFR 173.24a Additional general requirements for non-bulk packagings and packages.}

\section{$173.24 \mathrm{a}$ (a) Packaging Design.}

Except as provided in $\$ 172.312$ of this subchapter:

(1) Inner packaging closures. A combination packaging containing liquid hazardous materials must be packed so that closures on inner packagings are upright.

(2) Friction. The nature and thickness of the outer packaging must be such that friction during transportation is not likely to generate an amount of heat sufficient to alter dangerously the chemical stability of the contents.

(3) Securing and cushioning. Inner packagings of combination packagings must be so packed, secured and cushioned to prevent their breakage or leakage and to control their movement within the outer packaging under conditions normally incident to transportation. cushioning material must not be capable of reacting dangerously with the contents of the inner packagings.

(4) Metallic devices. Nails, staples and other metallic devices shall not protrude into the interior of the outer packaging in such a manner as to be likely to damage inner packagings or receptacles.

This requirement: [ ] Does not apply.

[ ] Applies; indicate the following.

Addressed in:

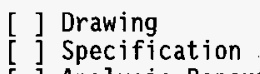

[ ] Operating Instruction

[ ] Analysis Report

Specify:

\subsection{4a (a) Packaging Design. (Continued)}

(5) Vibration. Each non-bulk package must be capable of withstanding, without rupture or leakage, the vibration test procedure specified in $\$ 178.608$ of this subchapter.

This requirement: [ ] Does not apply. Addressed in:
[ ] Applies; indicate the following.

[ ] Operating Instruction

[ ] Manufacturer Supplied Data [ ] Similarity or Documented Record

Specify: 


\title{
$173.24 a$ (b) Non-bulk Packaging Filling Limits.
}

\author{
(1) A single or composite non-bulk packaging may be filled with a liquid hazardous \\ material only when the specific gravity of the material does not exceed that marked on the \\ packaging, or a specific gravity of 1.2 if not: marked... \\ ... (2) Except as otherwise provided in this section, a single or composite non-bulk packaging \\ may not be filled with a solid hazardous material to a gross mass greater than the maximum \\ gross mass marked on the packaging. \\ (3) A single or composite non-bulk packaging which is tested or marked for liquid \\ hazardous materials may be filled with a solid hazardous material to a gross mass, in \\ kilograms, not exceeding the rated capacity of the packaging in liters, multiplied by the \\ specific gravity marked on the packaging, or 1.2 if not marked... \\ ... (5) No hazardous materiat may remain on the outside of a package after filling. \\ NOIE: Type A limits are identified in 49 CFR 173.443.
}

This requirement: [ ] Does not apply. Addressed in: Specify:
[ ] Applies; indicate the following.

[ ] Operating Instruction [ ] Manufacturer Supplied Data [ ] Similarity or Documented Record 


\section{$173.24 a$ (c) Mixed Contents.}

(1) An outer non-bulk packaging may contain more than one hazardous material only when-(i) The inner and outer packagings used for each hazardous material conform to the relevant packaging sections of this part appl icable to that hazardous material; (ii) The package as prepared for shipment meets the performance tests prescribed in part 178 of this subchapter for the packing group indicating the highest order of hazard for the hazardous materials contained in the package;

( $i$ ii) Corrosive materials (except ORM-D) in bottles are further packed in securely closed inner receptacles before packing in outer packagings; and

(iv) For transportation by aircraft, the total net quantity does not exceed the lowest permitted maximum net quantity per package as shown in Colum $9 a$ or $9 b$, as appropriate, of the $\$ 172.101$ Table. The permitted maximum net quantity must be calculated in kilograms if a package contains both a liquid and a solid.

(2) A packaging containing inner packagings of Division 6.2 materials may not contain other hazardous materials, except dry ice.

This requirement: [ ] Does not apply. [ ] Applies; indicate the following.

Addressed in: [ ] Drawing

[ ] Specification

[ ] Analysis Report

[ ] Operating Instruction
[ ] Manufacturer Supplied Data
[ ] Similarity or Documented Record

Specify:

\subsection{4a (d) Liquid Fill Level.}

Liquids must not completely fill a receptacle at a temperature of $55^{\circ} \mathrm{C}\left(131^{\circ} \mathrm{F}\right)$ or less.

This requirement: [ ] Does not apply. [ ] Applies; indicate the following. Addressed in:

[ ] Drawing
[ ] Specification
[ Analysis Report




\title{
4.0 49 CFR 173.24b Additional general requirements for bulk packagings.
}

\section{$173.24 b$ (a) Outage and Filling Limits.}

\begin{abstract}
(1) Liquids and liquified gases must be so loaded that the outage is at least one percent of the total capacity of a cargo or portable tank, or compartment thereof, or at least one percent of the total capacity of the tank and dome for tank car and mult $i$-unit tank car tanks at the reference temperature of $46^{\circ} \mathrm{C}\left(115^{\circ} \mathrm{F}\right)$ for uninsulated tanks and $41^{\circ} \mathrm{C}\left(105^{\circ} \mathrm{F}\right)$ for insulated tanks.

(2) Hazardous materials may not be loaded into the done of a tank car. If the dome of a tank car does not provide sufficient outage, vacant space must be left in the shell to provide the required outage.

(3) Bulk packagings for materials poisonous by inhalation. For a materiat which meets the definition of poisonous by inhalation (see $\$ 171.8$ of this subchapter), the outage in a bulk packaging must be at least five percent of the total capacity of the tank or compartment at the reference temperature of $46^{\circ} \mathrm{C}\left(115^{\circ} \mathrm{F}\right)$ for uninsulated tanks and $41^{\circ} \mathrm{F}\left(105^{\circ} \mathrm{F}\right)$ for insulated tanks.
\end{abstract}

This requirement: [ ] Does not apply.

Addressed in:

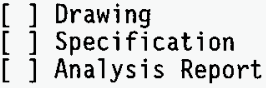

[ ] Applies; indicate the following.

[ ] Operating Instruction

[ ] Manufacturer Supplied Data ] Similarity or Documented Record

Specify: 


\subsection{4b (b) Stainless Steel Substitution.}

Equivalent steel. For the purposes of this section, stainless steel is steel with a guaranteed minimum tensile strength of 51.7 deka newtons per square millimeter $(75,000$ psi) and a guaranteed elongation of 40 percent or greater. Where the regulations permit steel other than stainless steel to be used in place of a specified stainless steel (for example, as in $\$ 172.102$ of this subchapter. special provision $B 30$ ), the minimum thickness for the steel must be obtained from one of the following formulas, as appropriate: Formula for metric units:

$e_{1}=\left(12.74 e_{0}\right) /\left(R m_{1} A_{1}\right)^{1 / 3}$

Formula for non-metric units:

$e_{1}=\left(144.2 e_{0}\right) /\left(R m_{1} A_{1}\right)^{1 / 3}$

Where:

$e_{0}=$ Required thickness of the reference stainless steel in millimeters or inches respectively;

$e_{1}=$ Equivalent thickness of the stee! used in millimeters or inches respectively; $\mathbf{R} \mathbf{m}_{4}=$ Specified minimm tensile strength of the steel used in deka newtons per square millimeter or pounds per square inch respectively; and

$A_{1}=$ Specified minimum percentage elongation of the steel used multiplied by 100 (for example, 20 percent times 100 equats 20 ). Elongation values used must be determined from a $50 \mathrm{~mm}$ or 2 inch tes't specimen.

This requirement: [ ] Does not apply.

[ ] Applies; indicate the following.

Addressed in:

[ ] Drawing
[ ] Specification
[ ] Analysis Report

[ ] Operating Instruction
[ ] Manufacturer Supplied Data
[ ] Similarity or Documented Record

Specify:

\subsection{4b (c) Pressurized Loading:}

Air pressure in excess of ambient atmospheric pressure may not be used to load or unload any lading which may create an air-enriched mixture within the flammability range of the lading in the vapor space of the tank.

This requirement: [ ] Does not apply.

[ ] Applies; indicate the following.

Addressed in:

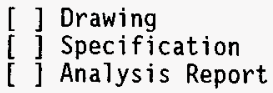

[ ] Operating Instruction

[ ] Manufacturer Supplied Data

Specify:

[ ] Similarity or Documented Record 
Docket :

WHC-SD-TP-RPT-017
Revision 1
DOT-7A TYPE A
PACKAGING QUALIFICATION CHECKLIST

173.24b (d) Design Temperature Range/Height:

A bulk packaging may not be loaded with a hazardous material that:

(1) is at a temperature outside of the packaging's design temperature range; or

(2) Except as otherwise provided in this subchapter, exceeds the maximum weight of lading marked on the specification plate.

This requirement: [ ] Does not apply. [ ] Applies; indicate the following.

Addressed in: [ ] Drawing

[ ] Specification

Specify:
[ ] Operating Instruction

[ ] Manufacturer Supplied Data

[ ] Similarity or Documented Record 


\subsection{CFR 173.410 General design requirements.}

\subsection{0(a) Handling and Securing.}

In addition to the requirements of subparts $A$ and $B$ of this part, each package used for the shipment of Class 7 (radioactive) materials must be designed so that--

(a) The package can be easily handled and properly secured in or on a conveyance during transport.

This requirement: [ ] Does not apply.

[ ] Applies; indicate the following.

Addressed in:

[ ] Drawing
$[$ ] Specification
$[$ ] Analysis Report

[ ] Operating Instruction

[ ] Similarity or Documented Record

Specify:

\subsection{0(b) Lifting Attachments.}

Each lifting attachment that is a structural part of the package must be designed with a minimum safety factor of three against yielding when used to lift the package in the intended manner, and it must be designed so that failure of any lifting attachment under excessive load would not impair the ability of the package to meet other requirements of this subpart. Any other structural part of the package which could be used to lift the package must be capable of being rendered inoperable for lifting the package during transport or must be designed with strength equivalent to that required for lifting attachments.

This requirement: [ ] Does not apply. [ ] Appilies; indicate the following.

Addressed in:
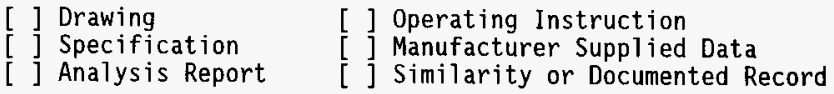

Specify: 


\subsection{0(c) External Surface Protrusions, Decontamination.}

The external surface, as far as practicable, will be free from protruding features and will be easily decontaminated.

This requirement: [ ] Does not apply. [ ] Applies; indicate the following.

Addressed in:

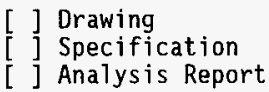

[ ] Operating Instruction
[ ] Manufacturer Supplied Data
[ ] Similarity or Documented Record

Specify:

\subsection{0 (d) Outer Layer - Pockets, Crevices (Water Collection).}

The outer layer of packaging will avoid, as far as practicable, pockets or crevices where water might collect.

This requirement: [ ] Does not apply. [ ] Applies; indicate the following.

Addressed in:

[ ] Drawing
[ ] Specification
[ ] Analysis Report

[ ] Operating Instruction

[ ] Manufacturer Supplied Data

[ ] Similarity or Documented Record

Specify: 


\subsection{0(e) Features Added at Time of Transport.}

Each feature that is added to the package will not reduce the safety of the package.

This requirement: [ ] Does not apply. [ ] Applies; indicate the following.

Addressed in: [ ] Drawing

[ ] Specification

[ ] Operating Instruction
[ ] Manufacturer Supplied Data
[ ] Similarity or Documented Record

Specify:

\subsection{0(f) Acceleration, Vibration.}

The package will be capable of withstanding the effects of any acceleration, vibration or vibration resonance that may arise under normal conditions of transport without any deterioration in the effectiveness of the closing devices on the various receptacles or in the integrity of the package as a whole and without loosening or unintentionally releasing the nuts, bolts, or other securing devices even after repeated use (see $\$ \$ 173.24,173.24 \mathrm{a}$, and $173.24 \mathrm{~b}$ ).

This requirement: [ ] Does not apply. [ ] Applies; indicate the following. Addressed in:

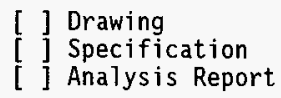

[ ] Operating Instruction
[ ] Manufacturer Supp Tied Data
[ ] Similarity or Documented Record

Specify: 


\subsection{0(g) Physical/Chemical Compatibility, Irradiation.}

The materials of construction of the packaging and any components or structure will be physically and chemically compatible with each other and with the package contents. The behavior of the packaging and the package contents under irradiation will be taken into account.

This requirement: [ ] Does not apply. [ ] Applies; indicate the following. Addressed in:

Specify:

\section{$173.410(h)$ Valve - Protection, Enclosure.}

All valves through which the package contents could escape will be protected against unauthorized operation;

This requirement: [ ] Does not apply.

Addressed in:

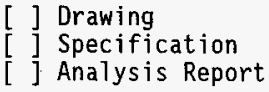

[ ] Applies; indicate the following.

[ ] Operating Instruction

[ ] Manufacturer Supplied Data

[ ] Similarity or Documented Record

Specify: 


\subsection{0(i) For Transport by Air--}

(1) The temperature of the accessible surfaces of the package will not exceed $50^{\circ} \mathrm{C}\left(122^{\circ} \mathrm{F}\right)$ at an ambient temperature of $38^{\circ} \mathrm{C}\left(100^{\circ} \mathrm{F}\right)$ with no account taken for insulation;

(2) The integrity of containment will not be impairec if the package is exposed to ambient temperatures ranging from $-40^{\circ} \mathrm{C}\left(-40^{\circ} \mathrm{F}\right)$ to $+55^{\circ} \mathrm{C}\left(131^{\circ} \mathrm{F}\right)$; and

(3) Packages containing liquid contents will be capable of withstanding, without leakage, an internal pressure that produces a pressure differential of not less than $95 \mathrm{kPa}\left(13.8 \mathrm{Lb} / \mathrm{in}^{2}\right)$.

This requirement: [ ] Does not apply. [ ] Applies; indicate the following.

Addressed in:

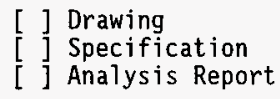

[ ] Operating Instruction

[ ] Manufacturer Supplied Data

[ ] Similarity or Documented Record

Specify: 


\subsection{CFR 173.412 Additional design requirements for Type A packages.}

\subsection{Tamper Indication.}

In addition to meeting the general design requirements prescribed in $\$ 173.410$, each Type A packaging must be designed so that --

(a) The outside of the packaging incorporates a feature, such as a seal, that is not

readily breakable, and that, while intact, is evidence that the package has not been

opened. In the case of packages shipped in closed transport vehicles in exclusive use, the cargo compartment, instead of the individual packages, may be sealed.

This requirement: [ ] Does not apply. [ ] Applies; indicate the following. Addressed in:
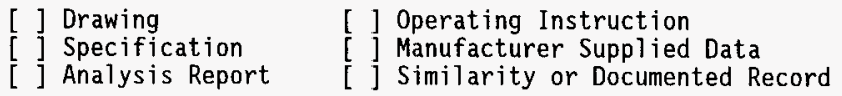

Specify:

\subsection{2(b) Smallest External Dimension.}

The smallest external dimension of the package is not less than 10 centimeters (4 inches);

This requirement: [ ] Does not apply. [ ] Applies; indicate the following.

Addressed in: [ ] Drawing

[ ] Specification

[ ] Analysis Report

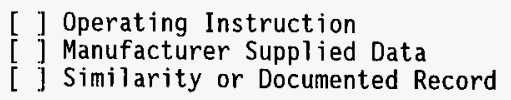

Specify: 
Docket :

WHC-SD-TP-RPT-017

Revision 1

DOT-7A TYPE A

PACKAGING QUALIFICATION CHECKLIST

\section{$173.412(c)$ Containment and Shielding.}

Containment and shielding is maintained during transportation and storage in a temperature range of $-40^{\circ} \mathrm{C}\left(-40^{\circ} \mathrm{F}\right)$ to $70^{\circ} \mathrm{C}\left(158^{\circ} \mathrm{F}\right)$. Special attention shall be given to liquid contents and to the potential degradation of the packaging materials within the temperature range.

This requirement: [ ] Does not apply. [ ] Applies; indicate the following.

Addressed in:

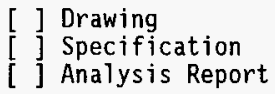

[ ] Operating Instruction
[ ] Manufacturer Supplied Data
[ ] Similarity or Documented Record

Specify:

\subsection{2 (d) Secure Containment System.}

The packaging must include a containment system securely closed by a positive fastening device that cannot be opened unintentionally or by pressure that may arise within the package during normal transport. Special form Class 7 (radioactive) material, as demonstrated in accordance with

$\$ 173.469$, may be considered as a component of the containment system. If the containment system

forms a separate unit of the package, it must be securely closed by a positive fastening device that is independent of any other part of the package.

This requirement: [ ] Does not apply. [ ] Applies; indicate the following. Addressed in:

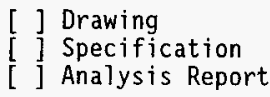
[ ] Operating Instruction
[ ] Manufacturer Supplied Data Jimilarity or Documented Record

Specify: 


\subsection{2(e) Radiolytic Decomposition, Chemical Reaction, Radiolysis.}

For each component of the containment system account is taken, where applicable, of radiolytic decomposition of materials and the generation of gas by chemical reaction and radiolysis.

This requirement: [ ] Does not apply. [ ] Applies; indicate the following.

Addressed in: [ ] Drawing

[ ] Specification

[ ] Analysis Report

[ ] Operating Instruction

[ ] Manufacturer Supplied Data

[ ] Similarity or Documented Record

Specify:

\subsection{2(f) Reduction of Ambient Pressure.}

The containment system will retain its radioactive contents under the reduction of ambient pressure to $25 \mathrm{kPa}$ ( 3.6 pounds per square inch).

This requirement: [ ] Does not apply. [ ] Applies; indicate the following. Addressed in:

Specify: 


\subsection{2(g) Valve - Protection, Enclosure.}

Each valve, other than a pressure relief device, is provided with an enclosure to retain any leakage.

This requirement: [ ] Does not apply.

[ ] Applies; indicate the following.

Addressed in:

[ ] Drawing
[ ] Specification
[ ] Analysis Report

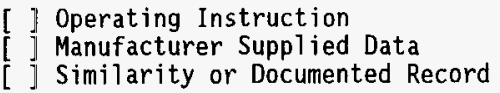

Specify:

\subsection{2(h) Shielding (Enclosure).}

Any radiation shield that encloses a component of the packaging specified as part of the containment system will prevent the unintentional escape of that component from the shield.

This requirement: [ ] Does not apply.

Addressed in:

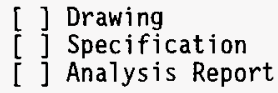

[ ] Applies; indicate the following.

[ ] Operating Instruction

[ ] Manufacturer Supplied Data

] Similarity or Documented Record

Specify: 


\subsection{2(i) Tiedown (Failure).}

Failure of any tie-down attachment that is a structural part of the packaging, under both normal and accident conditions, must not impair the ability of the package to meet other requirements of this subpart.

This requirement: [ ] Does not apply.

[ ] Applies; indicate the following.

Addressed in:

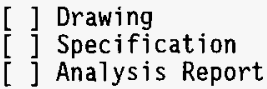

[ ] Operating Instruction
[ ] Manufacturer Supplied Data
[ ] Similarity or Documented Record

Specify:

\section{$173.412(j) \quad$ Evaluation and Testing.}

When evaluated against the performance requirements of this section and the tests specified in $\$ 173.465$ or using any of the methods authorized by $\$ 173.461$ (a), the packaging will prevent--

(1) Loss or dispersal of the radioactive contents; and

(2) A significant increase in the radiation level's recorded or calculated at the external surfaces for the condition before the test.

NOTE: A significant increase may be defined as, "Loss of shielding integrity which would result in more than a 20 percent increase in the radiation level at any external surface of the package" (IAEA Safety Series No. 6, Paragraph No. 537, 1985 Edition).

This requirement: [ ] Does not apply. [ ] Applies; indicate the following. Addressed in:
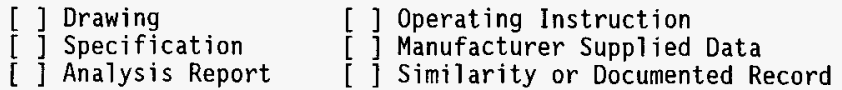

Specify: 


\subsection{2(k)(1) Design Requirement for Liquid Packagings.}

Each packaging designed for liquids will--

(1) Be designed to provide for ullage to accomodate variations in temperature of the contents, dynamic effects and filling dynamics;

This requirement: [ ] Does not apply. [ ] Applies; indicate the following. Addressed in:

Specify:

\subsection{2(k)(2) Evaluation and Testing of Liquid Packagings.}

Meet the conditions prescribed in paragraph ( $j$ ) of this section when subjected to the tests specified in $\$ 173.466$ or evaluated against these tests by any of the methods authorized by $\$ 173.461(a) ;$ and

This requirement will be addressed by the test facility. 


\subsection{2(k)(3) Choice of Design Requirement for Liquid Packagings.}

Either-

(i) Hove sufficient suitable absorbent material to absorb twice the volume of the liquid contents. The absorbent material must be compatible with the package contents and suitably positioned to contact the liquid in the event of leakage; or

(ii) Have a containment system composed of primary. inner and secondary outer containment components designed to assure retention of the Liquid contents within the secondary outer component in the event that the primary inner component leaks.

This requirement: [ ] Does not apply. [ ] Applies; indicate the following.

Addressed in:

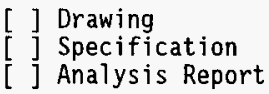

[ ] Manufacturer Supplied Data

[ ] Similarity or Documented Record
[ ] Operating Instruction

Specify:

\subsection{2(1) Evaluation and Testing of Gas Packagings.}

Each packaging designed for gases, other than tritium not exceeding 40 JBq (1000 $C_{i}$ ) or noble gases not exceeding the $A 2$ value appropriate for the noble gas, will be able to prevent loss or dispersal of contents when the package is subjected to the tests prescribed in $\$ 173.466$ or evaluated against these tests by any of the methods authorized by $\$ 173.461$ (a).

This requirement will be addressed by the test facility. 


\subsection{CFR 178.3 Marking of Packagings}

\section{3 (a) What and How to Mark.}

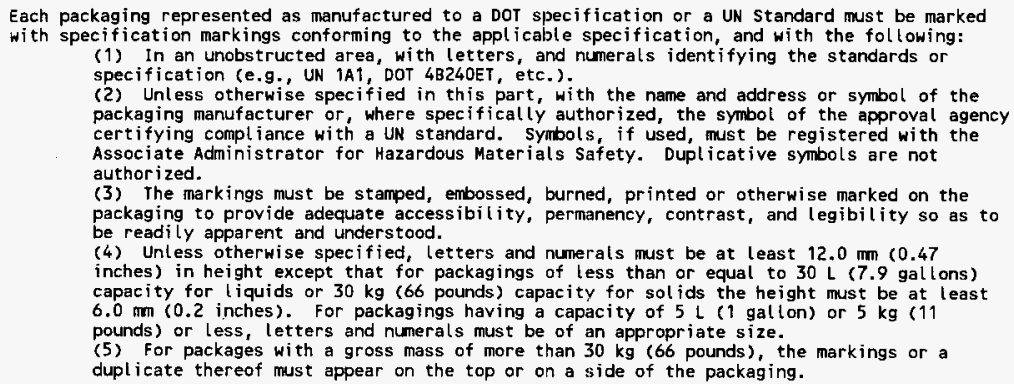

This requirement: [ ] Does not apply. [ ] Applies; indicate the following. Addressed in:
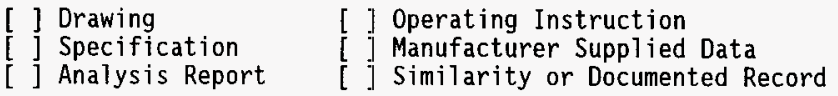

Specify: 


\section{3(b) Marking.}

A UN standard packaging for which the UN standard is set forth in this part may be marked with the United Nations symbol and other specification markings only if it fully conforms to the requirements of this part. A UN standard packaging for which the lJN standard is not set forth in this part may be marked with the United Nations symbol and other specification markings for that standard as provided in the ICAO Technical Instructions or Annex 1 of the IMDG Code subject to the following conditions:

(1) The U.S. manufacturer must establish that the packaging conforms to the applicable provisions of the ICAO Technical Instructions or Annex 1 of the IMDG Code, respectively. (2) If an indication of the name of the manufacturer or other identification of the packaging as specified by the competent authority is required, the name and address or symbol of the manufacturer or the approval agency certifying compliance with the UN standard must be entered. Symbols, if used, must be registered with the Associate Administrator for Hazardous Materials Safety.

(3) The letters "USA" must be used to indicate the State authorizing the allocation of the specification marks if the packaging is manufactured in the United States.

This requirement: [ ] Does not apply. [ ] Applies; indicate the following.

$\begin{array}{lll}\text { Addressed in: } & {[\text { ] Drawing }} & \text { [ ] Operating Instruction } \\ & {[\text { [ Specification }} & \text { [ ] Manufacturer Supplied Data } \\ & \text { [ ] Analysis Report } & \text { [ ] Similarity or Documented Record }\end{array}$

Specify:

\section{3(c) Multiple Markings.}

Where a packaging conforms to more than one UN standard or DOT specification, the packaging may bear more than one marking, provided the packaging meets all I the requirements of each standard or

specification. Where more than one marking appears on a packaging, each marking must appear in its entirety.

This requirement: [ ] Does not apply. [ ] Applies; indicate the following.

Addressed in: [ ] Drawing

[ ] Specification

[ ] Analysis Report
[ ] Operating Instruction

[ Manufacturer Supplied Data

[ Similarity or Documented Record

Specify: 


\subsection{Proof Testing By Sponsor}

Please mark the appropriate box(es) shown below to identify any proof testing that has been completed prior to providing test packages to the DOEapproved test facility for Type A testing. If any documentation exists from the proof testing conducted, the sponsor should include that information along with this checklist.

[ ] Reduction in ambient (external) pressure or equivalent

Method:

Pressure:

Duration:

[ ] Vibration

Duration:

[ ] Water Spray Inches:

Duration:

[ ] Compression Weight:

Duration:

[ ] Penetration Height:

Location:

[ ] Free Drop Height:

\# of Drops:

Orientation:

\subsection{Other Items}

Enclose a copy of the following documents, along with this completed checklist, and forward to the DOE/HQ-approved test facility. The name and address of the test facility are provided when a docket is opened as discussed in Section 5.0:

- Packaging drawing

- Packaging specification (if developed)

- Analysis report

- Operating instruction 


\section{Completion}

Appl icant :

Signature Date

Name (print)/

Company/Address

Phone:

E-Mai1 Address:

Test Facility Use Only

Document review:

Packaging drawing

Packaging specification

Analys is report

Operating instruction

Packaging Qualification Checklist

Proof testing (sponsor) 